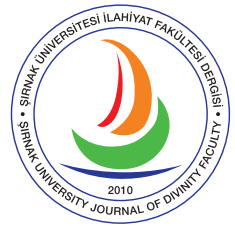

\title{
أثر اللجوء في الأدب العربي المعاصر المأساة السورية أنموذجاً
}

\section{Suriye Trajedisi Örneğinde Çağdaş Arap Edebiyatında Göç ve İltica} Migration and Asylum in Contemporary Arabic Literature with the Example of Syrian Tragedy

\section{Majed Haj Mohammad}

Dr. Öğr. Üyesi, Hakkâri Üniversitesi, İlahiyat Fakültesi, Arap Dili ve Belagatı Ana Bilim Dalı Assistant Professor, Hakkari University, Faculty of Theology, Departmant of Arabic Langauge and Rhetoric Hakkâri, Turkey

halap-200200@hotmail.com https://orcid.org/0000-0003-3315-712X

\section{Makale Bilgisi / Article Information}

Makale Türü / Article Types: Araştırma Makalesi / Research Article

Geliş Tarihi / Received: 1 Şubat / February 2020

Kabul Tarihi / Accepted: 30 Mart / March 2020

Yayın Tarihi / Published: 15 Haziran / June 2020

Cilt / Volume: 11 Sayı / Issue: 24 Sayfa / Pages: 260-280

Atıf / Cite as: Haj Mohammad, Majed. "Eseru'-Lucûi fi'l-Edebi'l-Arabiyyi'l-Mu'âsır [Migration and Asylum in Contemporary Arabic Literature with the Example of Syrian Tragedy]". Şırnak Üniversitesi İlahiyat Fakültesi Dergisi - Şırnak University Journal of Divinity Faculty 11/24 (June 2020), 260-280. https://doi.org/10.35415/sirnakifd.683331

Etik Beyanı / Ethics Declaration: Bu makalede bilimsel araştırma ve yayın etiği ilkelerine riayet edilmiştir. Makale etik izin gerektirmeyen bir çalışma olup en az iki hakem tarafından incelenmiş ve intihal içermediği teyit edilmiştir./ In this article, the principles of scientific research and publication ethics are respected. The article is a study that does not require ethical permission. It has been reviewed by at least two referees and was confirmed that it did not contain plagiarism.

Copyright () Published by Şırnak Üniversitesi, İlahiyat Fakültesi / Şırnak, Türkiye (Şırnak University, Faculty of Divinity, Şırnak, 73000 Turkey). 


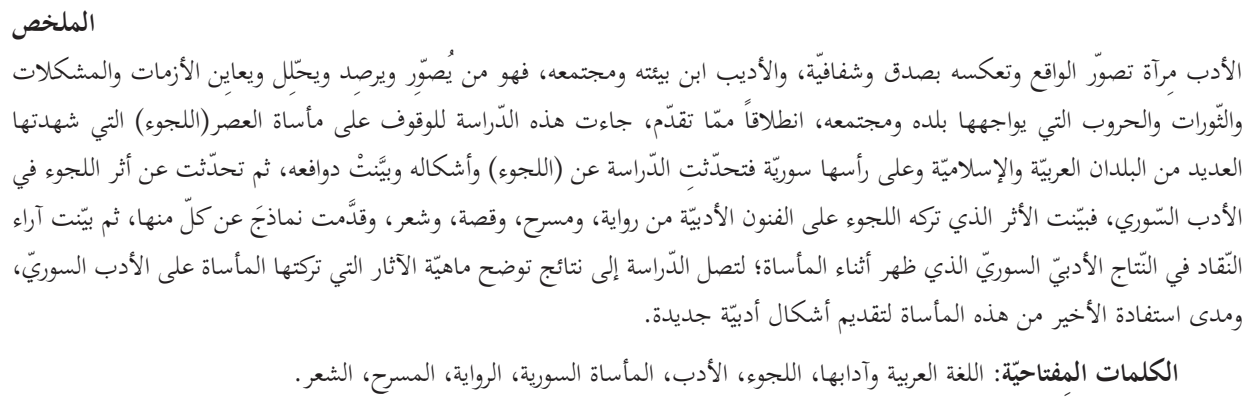

\title{
Öz
}

Edebiyat gerçekliğin ve toplumsal olayların aynasıdır. Vakıa ve gerçeklik edebiyatta şeffaf ve açık olarak yansımaktadır. Bu yüzden edebiyatçı yaşadığı toplumun ve çevrenin ürünüdür. Edebiyatçı yaşadığı toplumun karşılaştığı devrimleri, savaşları, krizleri ve sorunları gözlemleyen, tasvir eden, tahlil eden ve bunlara çözüm arayan kimsedir. Kimi edebiyatçılar yaşadıkları sorunlardan bizzat etkilenirler ve bu etkilenme aynı zamanda daha etkili eserler vermesini sağlayabilir. Nitekim dünya edebiyatında bunun birçok örneği de vardır. Bu bağlamda çalışmamız başta Suriye olmak üzere birçok İslam Arap ülkesinin günümüzde karşılaştı̆̆ı iltica ve göçten kaynaklı trajedilerine değinmektedir. Bu noktada iltica ve göçün mülteciler ve onların iltica ettikleri ülkeler üzerindeki etkisi; iltica ve göçün nedenleri, mültecilerin karşılaştığı zorluklar ve ihtiyaçları irdelenecektir. Bu Çalışmada Çağdaş Arap Edebiyatının, Suriyeli mültecilerin trajedilerini uluslararası ve Arap okuyuculara tasvir etme ve aktarma konusundaki etkisi Suriye Edebiyatının farklı örnekleri (roman hikâye, şiir) çerçevesinde ele alınmaktadır. Daha sonra bu acılarla yoğrulan Suriye edebiyatı ile ilgili eleştirmenlerin görüşleri incelenerek üzerindeki etkileri ortaya çıarılacak ve yeni edebiyat türlerine işık tutacaktır.

Anahtar Kelimeler: Arap Dili ve Belagatı, Göç, Edebiyat, Suriye Trajedisi, Roman, Tiyatro, Şiir.

\begin{abstract}
Literature is a mirror of verity and the facts. The fact and the verity are reflected in literature in a sheer and explicit manner. Author is the product of the society and environment in which he lives. Author is the person who observes, depicts, analyzes and seeks solutions to the revolutions, wars, crises and problems faced by the society in which he located in. In this context, our study refers to the tragedies of asylum and immigration, which are now faced by many Islamic Arab countries, especially Syria. At this point, the impact of asylum and migration on refugees and their asylum countries; the causes of asylum and migration, arduousnesses faced by refugees and their needs will be discussed. In this study, the impact of contemporary Arabic literature on portraying and transferring the tragedies of Syrian refugees to both international readers and Arab readers is discussed within the framework of different examples of Syrian literature (novel, story, poetry). Afterwards, the views of critics about the Syrian literature, which is impasted with these griefs, will be examined and their effects on this literature will be revealed and will shed light on the new types of literature.
\end{abstract}

Keywords: Arabic Language and Rhetoric, Migration, Literature, Syrian Tragedy, Novel, Theater, Poetry. 


\section{Extended Abstract}

The Arab literary body in general, and the Syrians in particular in the last nine years, worked on achieving a literary text that stems from the calamities and calamities that befell the Arab and Islamic nation, From the American invasion of Afghanistan, Somalia and Iraq, to the Arab Spring, which sparked from Tunisia and passed in Egypt, Libya, Yemen and many Arab countries, However, she landed her journey in Syria, and she refused to leave her after her children 's throats first word of freedom, subjected them to severe arrest and repression, And an unprecedented displacement, which forced many of them to knock on the doors of sister and friendly neighboring countries, or ride death (the sea) to reach Europe. And because literature is a mirror of society, And emerging from the womb of the living reality with all its social and political dimensions and dimensions, He took it upon himself to convey a very realistic and accurate picture of the tragedy of the Syrian people, And his suffering in front of the killing, destruction and displacement machine, Without allowing the imagination to circumvent ideas and falsify what is happening on the ground, Rather, the reader was placed in a literary, artistic way in front of a real world, casted by an interesting narrative character; To know the facts and facts through him.

The novel - which is considered in the last decades as one of the most widely circulated literary forms and expressions of the Arab environment and its historical, social, real and political events - topped the Syrian literary arts in highlighting the events that the country has gone through, I photographed many aspects of the tragedy, and tried to capture the moments of the Nakba, And especially the moments of asylum and running away from death to a life where the fugitive could find the least safety and tranquility.

Based on the foregoing, the study asked several questions, including: What is asylum? What are his motives? Did literature, events and calamities in a people affect literature? And to what extent was literature able to depict the people's miseries and sufferings in the face of injustice and repression? Are there literary works dealing with these subjects? In addition to other questions related to the impact of the tragedy of asylum and war on Syrian literature, they were as follows: Has the Syrian writer dared to cross the red lines, break down barriers, and bypass taboos on political and social issues? What are the topics created by these tragedies, and prompted writers to realize their imagination in their depiction? 
As for the aims of the study, they were to unveil the tragedy that befell the Syrian people. Especially asylum, and sought to reveal its causes and motives, And I tried to show its impact on the arts of Syrian literature in general, such as theater and poetry, and narrative art in particular. As for its importance lies in its being one of the few studies that have stood on numerous and varied literary works, I photographed the tragedy that afflicted the Syrian people, And it showed its impact on the development and the qualitative shift that occurred for Syrian literature, After most literary works depicted the difficulties of life for the Syrian citizen, It touches on emotional, sexual or national issues. This tragedy shocked and shaken the world of Syrian literature. So, the writer freed himself from all the chains that were shackling him and started expressing what was going on in his chest. The pictures of tyranny, oppression, injustice and murder that afflicted his countrymen, He would not have reached the diversity he had reached in the subjects he included in his narrative text had it not been for his departure from the instrument of oppression, And his asylum to neighboring countries, or places outside the control of the system. In our study, we have followed this descriptive analytical approach based on studying the phenomenon of asylum. Probing, diagnosing, and analyzing, and presented its impact on the arts of Syrian literature in general, and novel art in particular.

Based on the above mentioned in the hadith about the novel, theater and poetry, the study reached several results, the most important of which are: Literature is a mirror reflecting reality in all its details. The tragedies experienced by peoples were able to influence literary arts such as novel, poetry and theater. Literature tried to monitor the tragedies and calamities of its countries, However, he faced many difficulties, including: The ambiguous position of some writers, after some were forced to leave the country under threat by all sides. The emergence of a literary category that tried to benefit from the Syrian tragedy through some poems and narrations, as a desire to seize the spotlight, or out of partisanship and intolerance to narrow party beliefs or ideas that you believe in. 


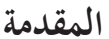

اشتغل المتن الأدبي العربي عامة، والسوري خخاصة في السنوات التسع الأخيرة عِلى إنجاز

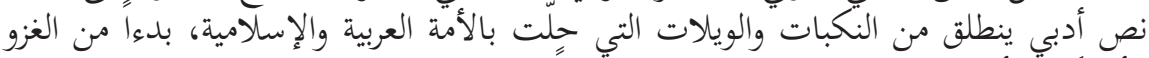

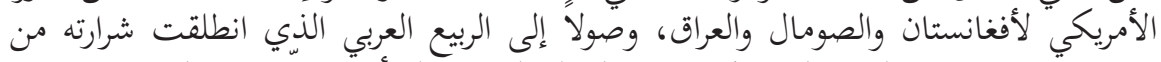

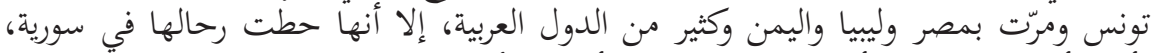

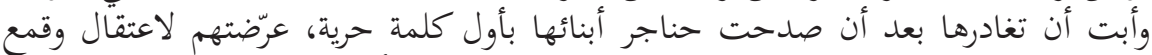

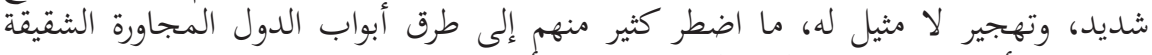
والصديقة، أو ركوب الموت الميل (البحر) للوصول إلى ألى أوربا.

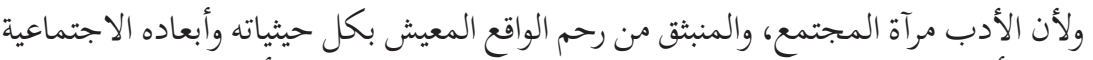

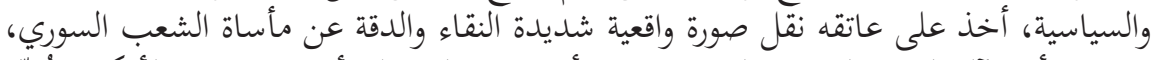

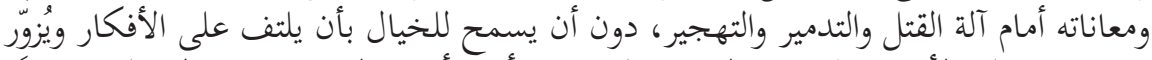

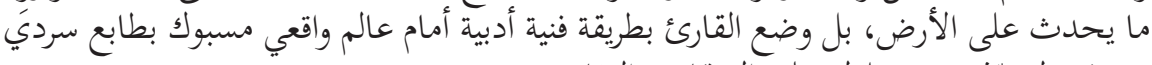

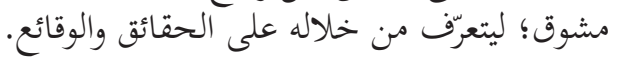

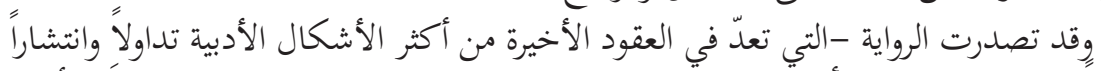

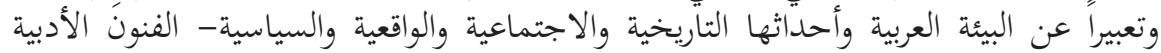

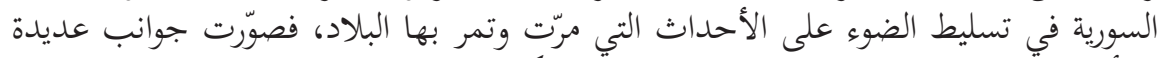

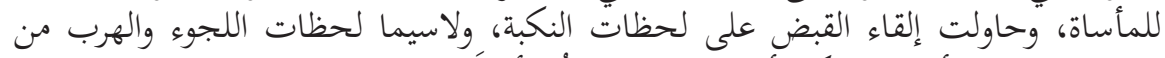

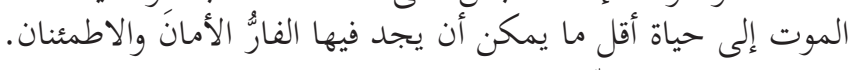

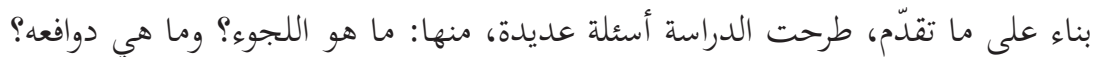

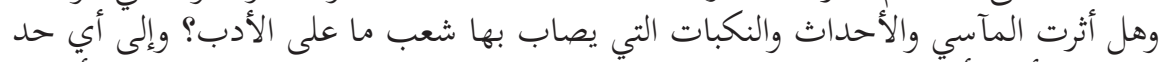

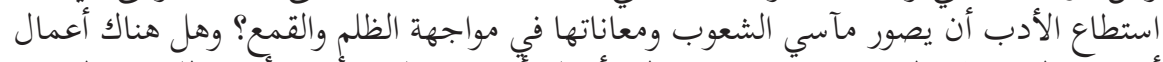

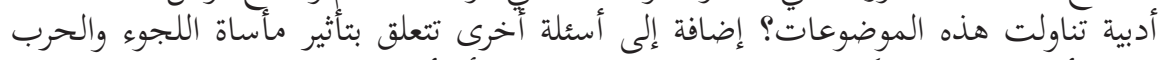

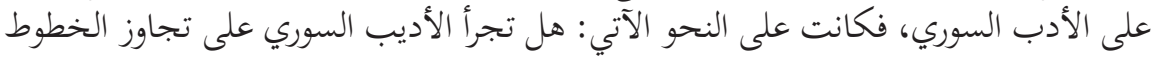

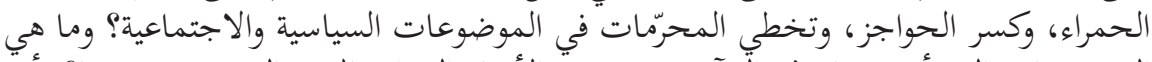

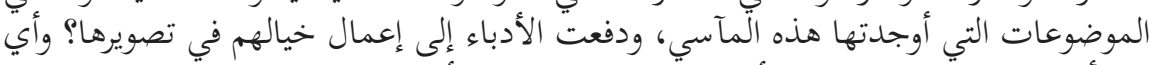

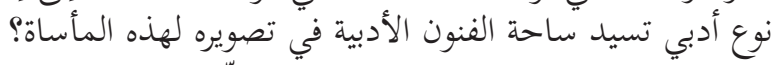

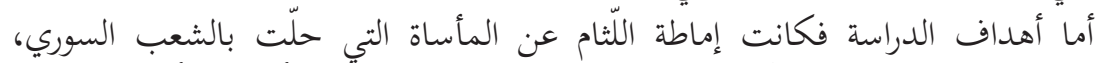

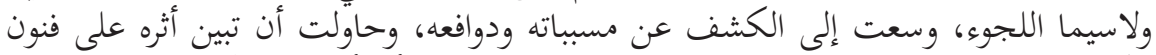

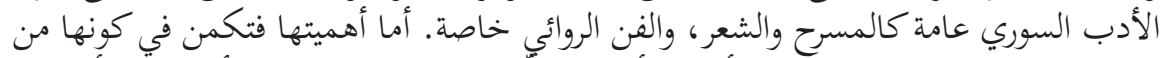

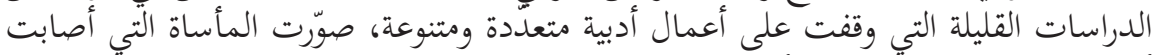

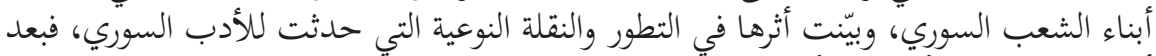

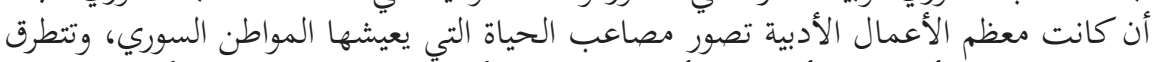

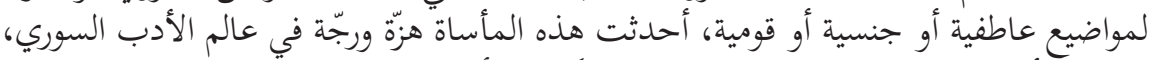

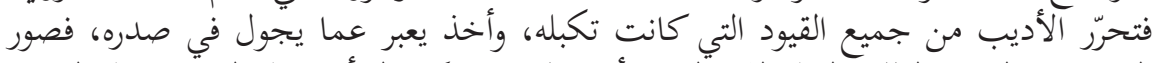

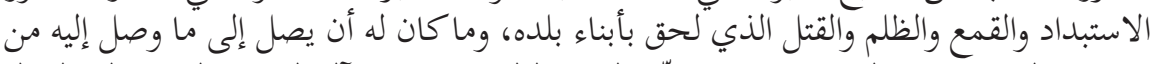

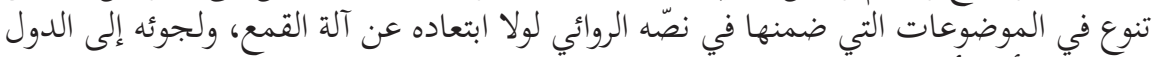

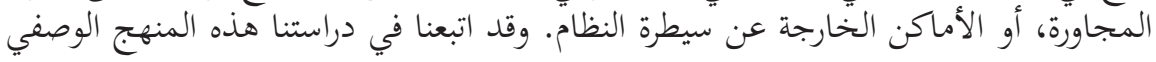


التحليلي القائم على دراسة ظاهرة اللجوء، وسبر أغوارها، وتشخيصها، وتحليلها، وعرض أثرها على فنون الأدب السوري عامة، والى دراسل طاهة الفي الرو، وائي خاصة.

اللجوء، رصد المفهوم

من أجل الوقوف على سرديات المأساة السرية، ينبغي علينا أن نحدد أولا معنى اللجوء المعاء

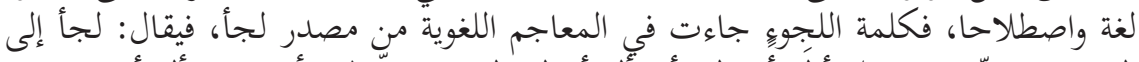

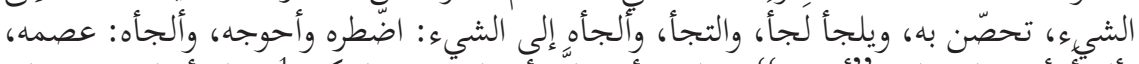

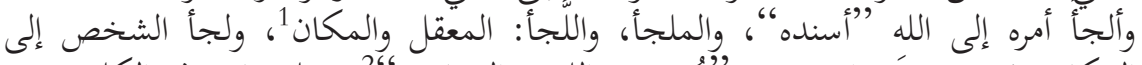

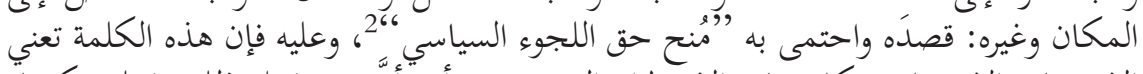

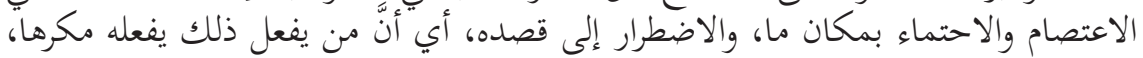
ليس رغبة وإنما رهبة.

وأما اللجوء اصطلاحاً: هو النماً رهبة الحماية التي تمنحها دولة فوق أراضيها أو فوق أي مكان

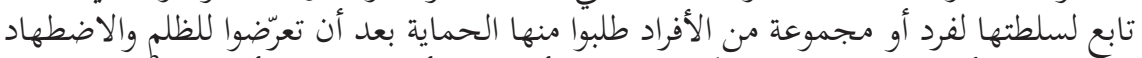

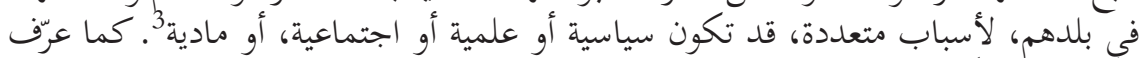

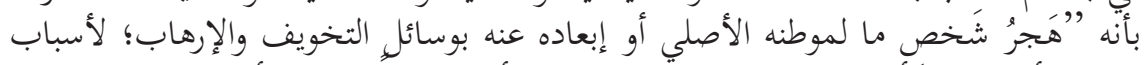

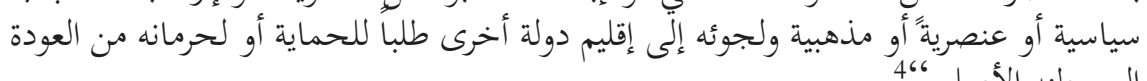

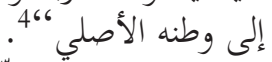

المأساة أداة خَّلاقة في الأدب

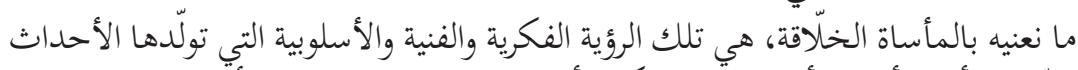

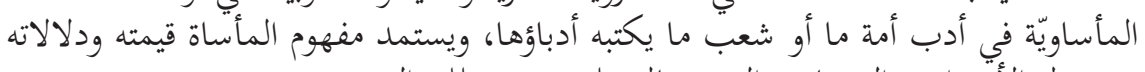

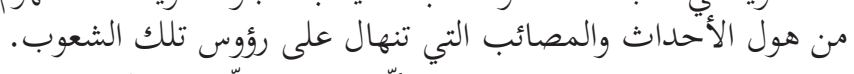

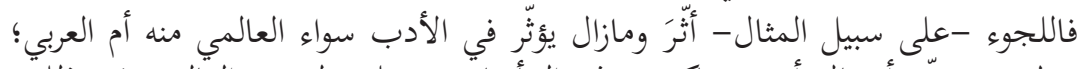

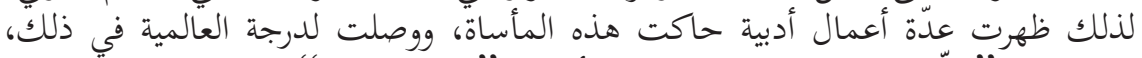

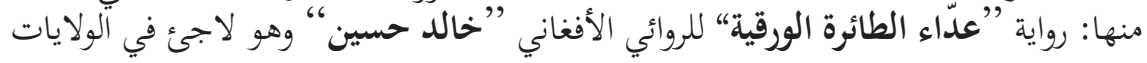

ينظر : ابن سيده، أبو الحسن علي بن إسماعيل المرسي، المحكم والمحيط الأعظم، ت: عبد الحميد هنداوي، دار

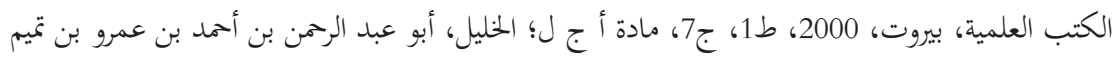

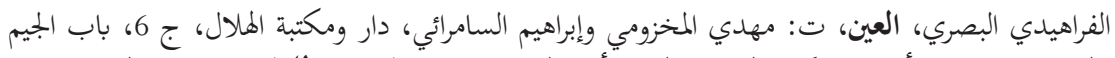

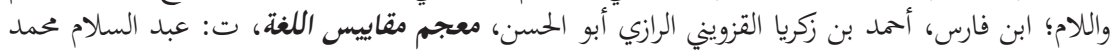

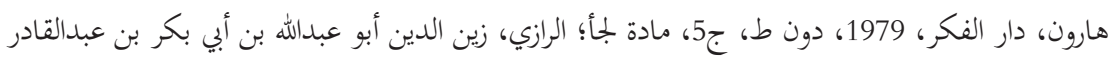

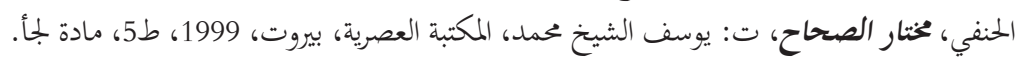

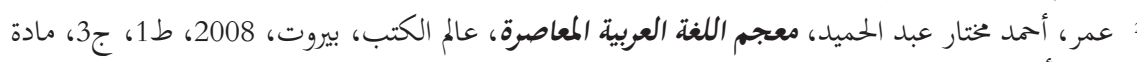

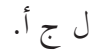

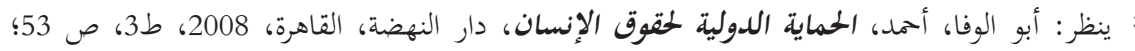

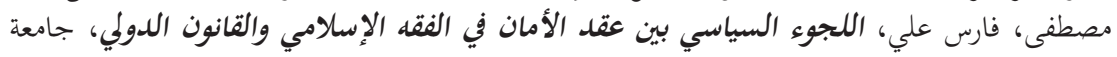

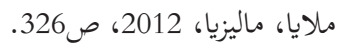
4 عطية الله، أحمد، القاموس السياسي، دار النهضة، القاهرة، ط3، دون ت، ص1044. 
المتحدة الأمريكية، عُدَّ من رواد أدب اللجوء؛ كونه قدّم رواية رائعة تروي قصة طفلين صغيرين

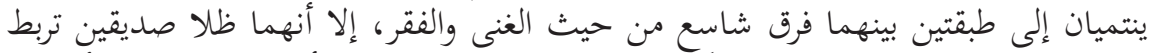

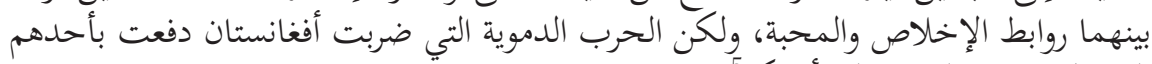

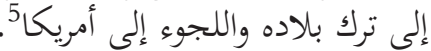

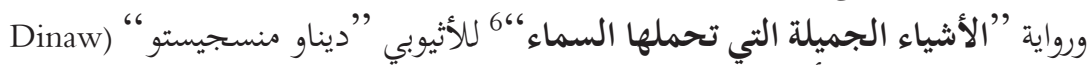
Mengestu

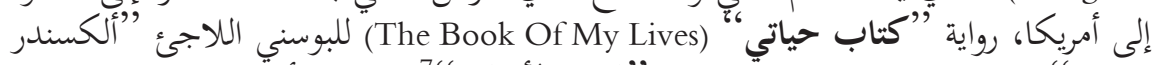

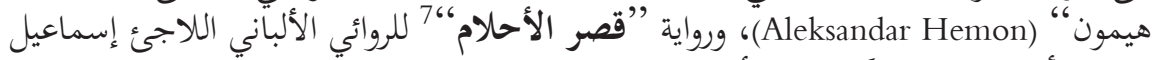

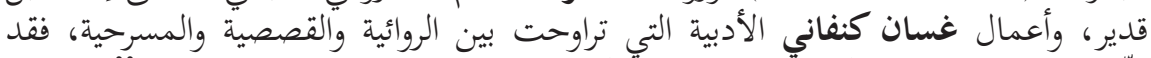

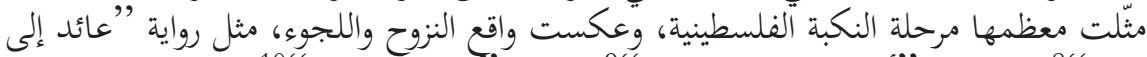

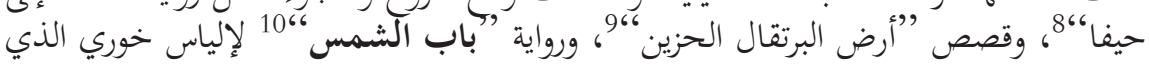

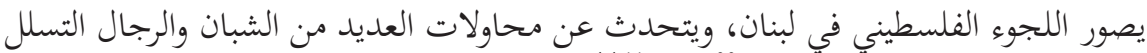

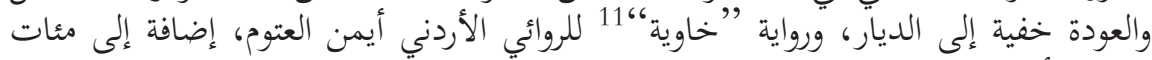
الرواية الأخرى التي ضاق المقام عن ذكرها.

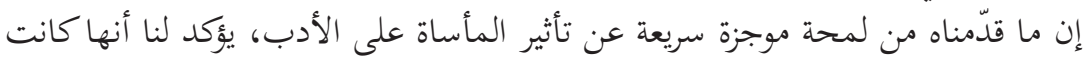

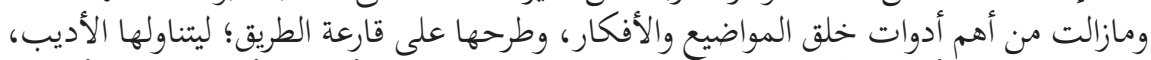

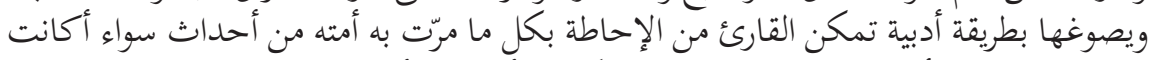

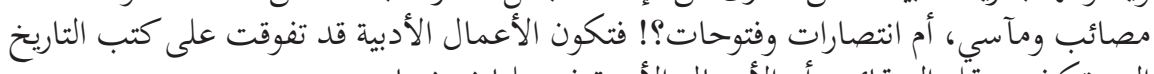

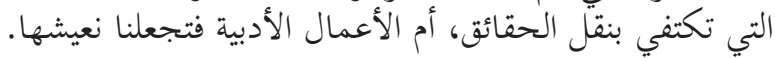

\section{تأثر الأدب السوري باللجوي}

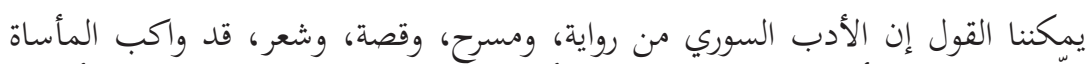

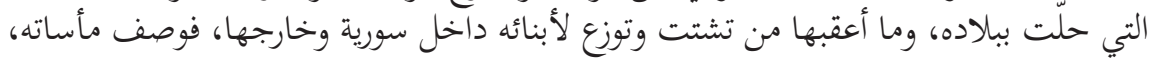

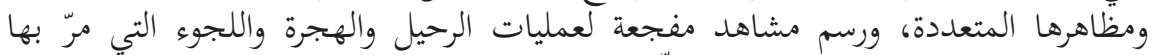

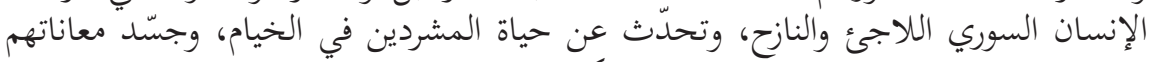

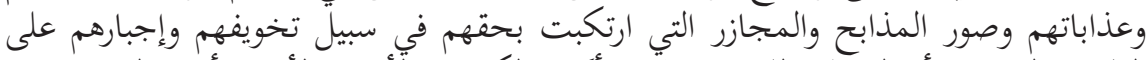

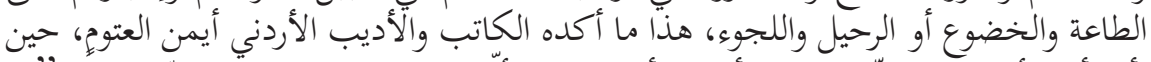

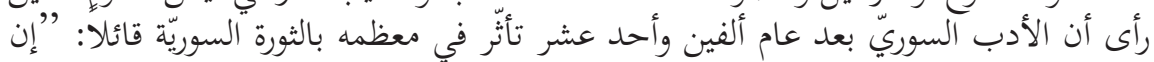

5 حسيني، خالد، عدّاء الطائرة الورقية، ت: خالد حسيني، دال للنشر والتوزيع، 2010، ط1 الن. Mengestu, Dinaw, The beautiful things that heaven bears, Riverhead Books, New York, 2007.

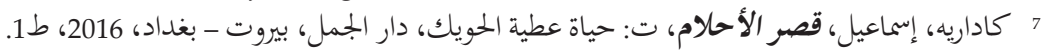

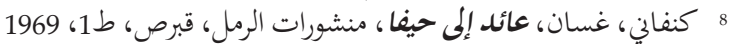

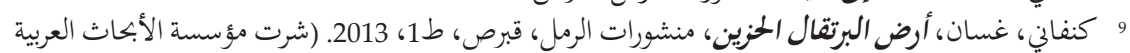

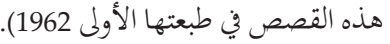

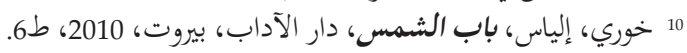

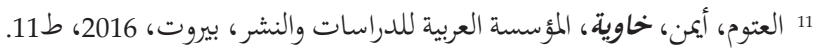


الأدب الذي نشأ بعد الثورة؛ ركّز في معظمه على الأسباب التي دفعتِ الشعب السوري إلى

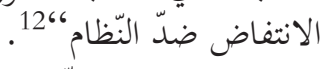

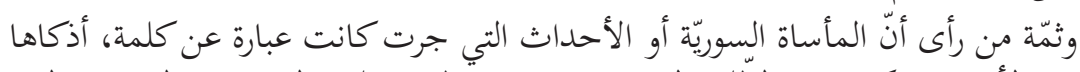

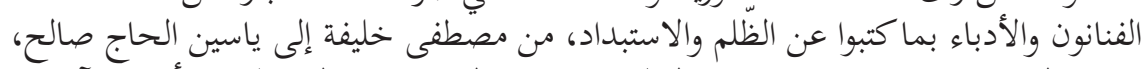

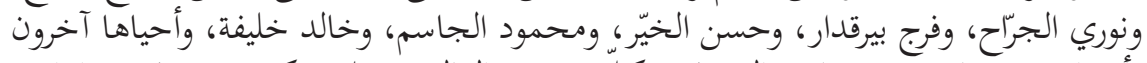

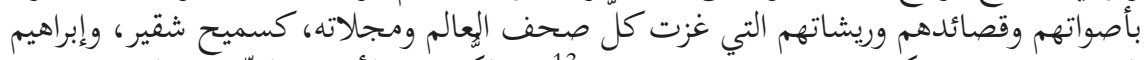

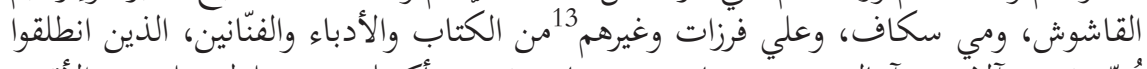

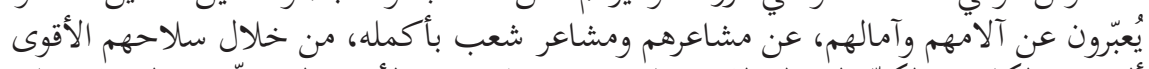

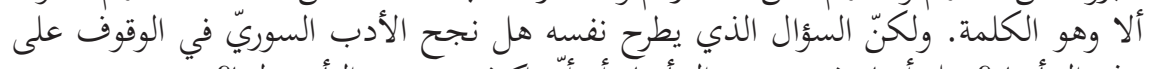

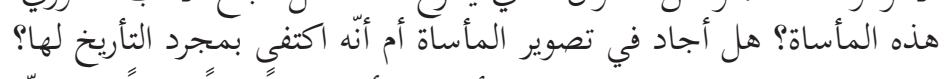

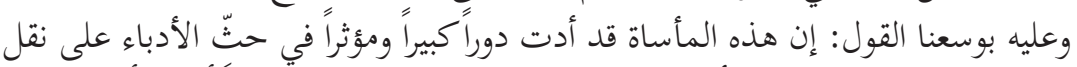

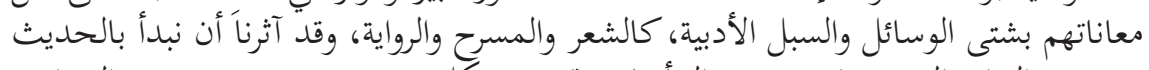

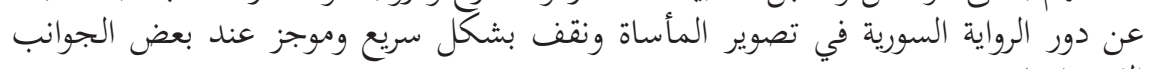
الفنية فيها. الرواية

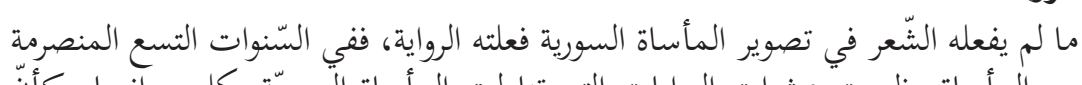

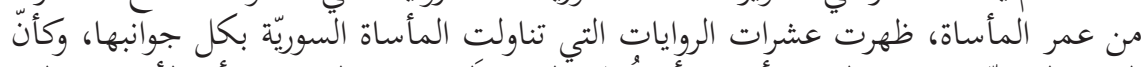

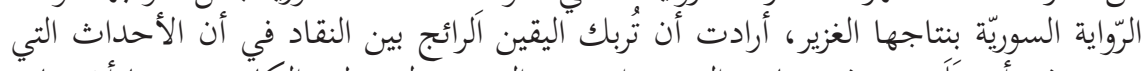

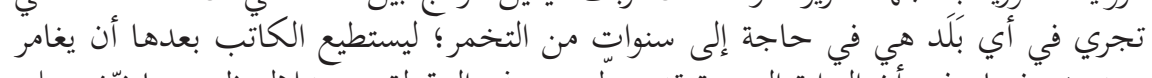

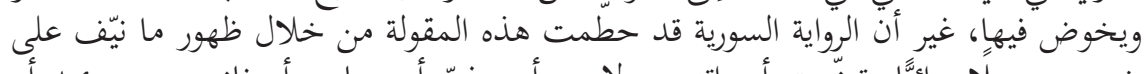

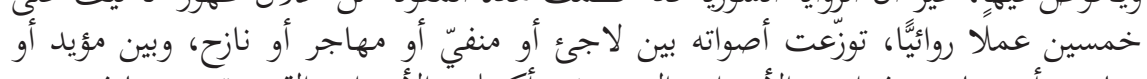

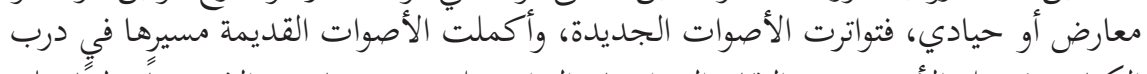

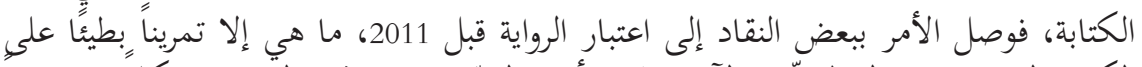

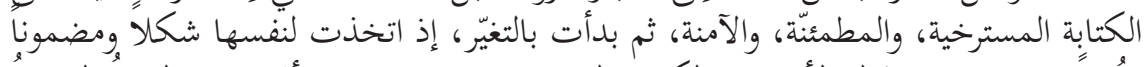

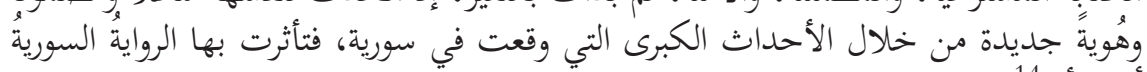
أيما تأثر 14.

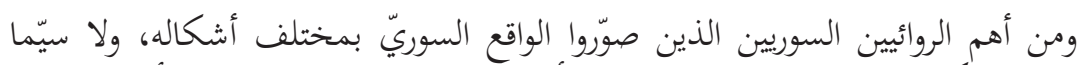

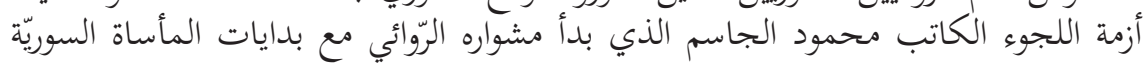

12 حميدة، معاذ، الأدب في زمن الثورة "سوريا نموذجاً"، موقع عربي21، بتاريخ https://arabi21.com/story. 13 حسين، هيثم، دور الأدب والثقافة في واقع الحرب والدمار، موقع الجزيرة، بتاريخ

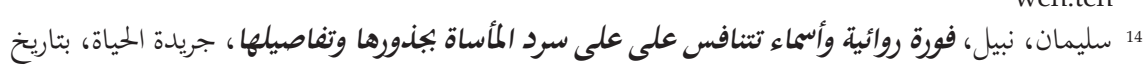


بعدة روايات من أهمها "لاجئة بين زوجين، 15، (2016)، وغفرانك يا أمي (2014) (2014)، ونزوحٍ

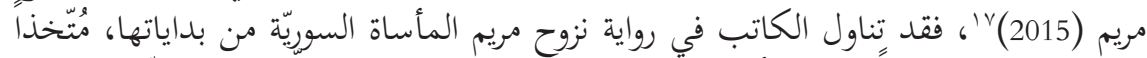

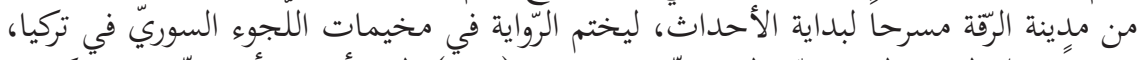

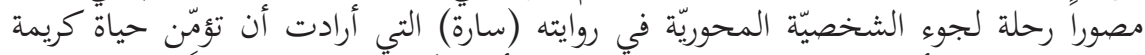

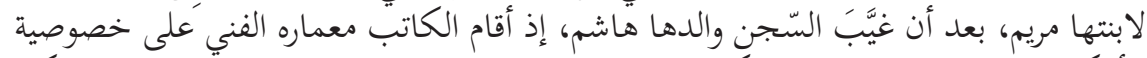

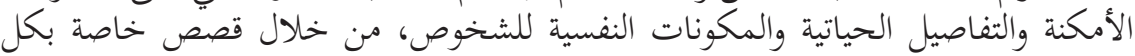

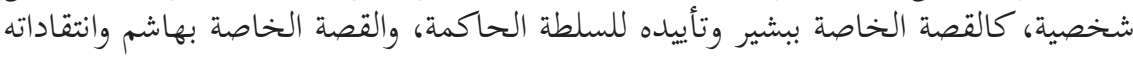

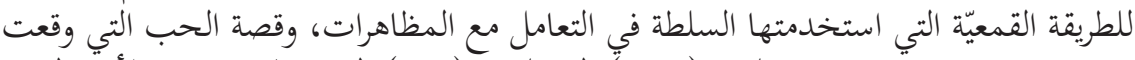

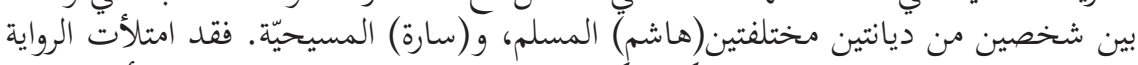

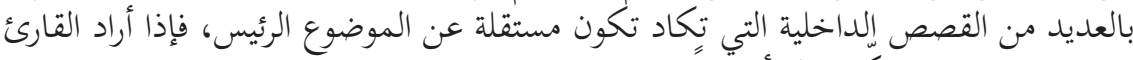
نزعها من سياقها، شكلت له أحدَّاثاً مستقلة.

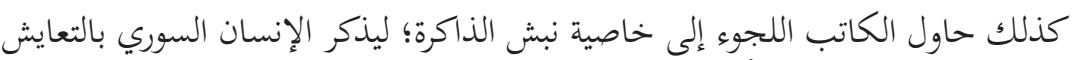

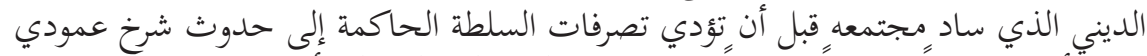

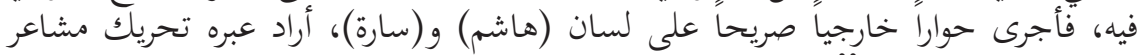

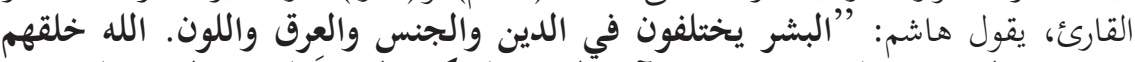

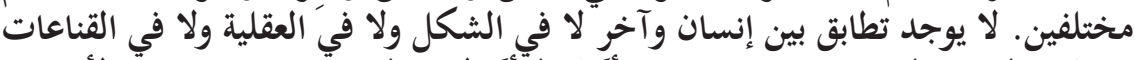

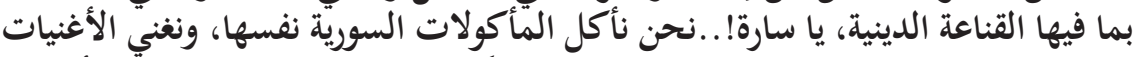

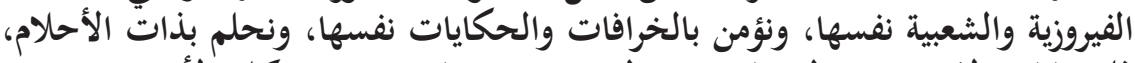

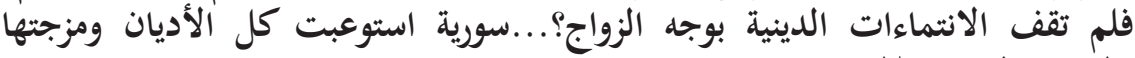

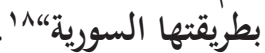

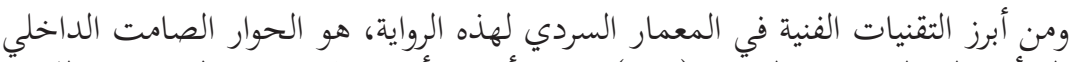

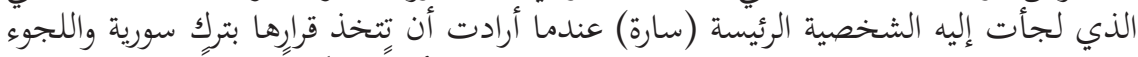

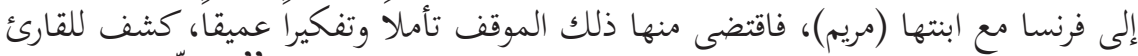

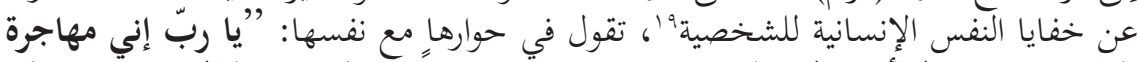

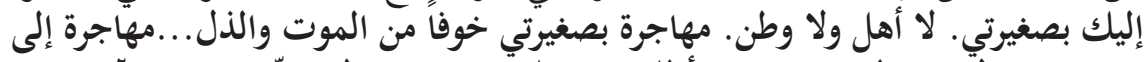

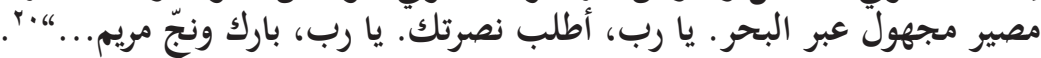

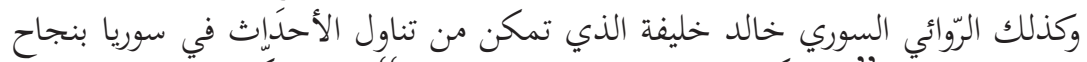

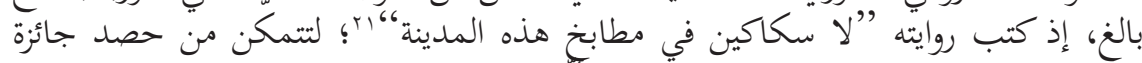
نجيب محفوظ للرواية العربية عام 2013م، كما أنها وصلت إلى هـئ القائمة القصيرة للجائزة العالمية

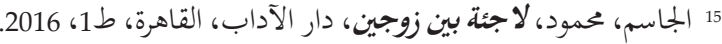

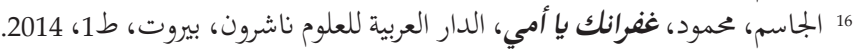

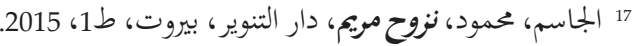

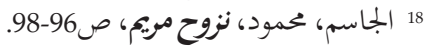
19 عتيق، عمر، قضايا نقدية معاصرة في الرواية والقصة القصيرة، دار دجلة، عمان، 2016، دون ط، ص79- 


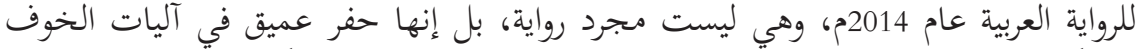

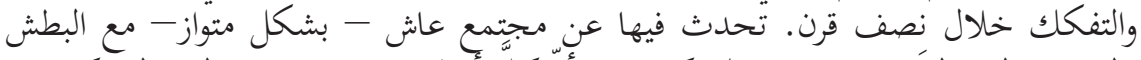

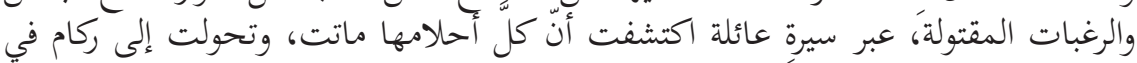
ظل نظام قمعي.

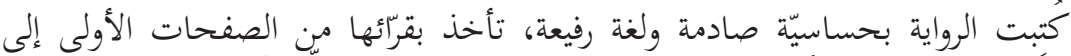

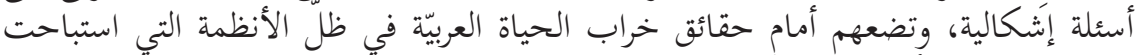

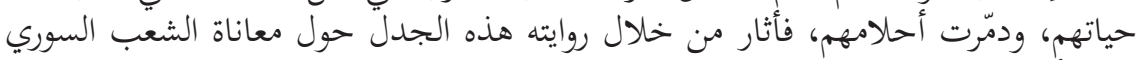

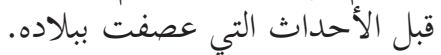

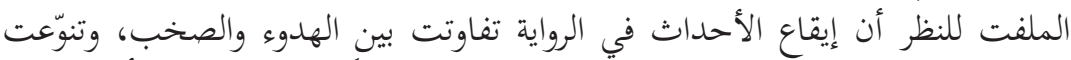

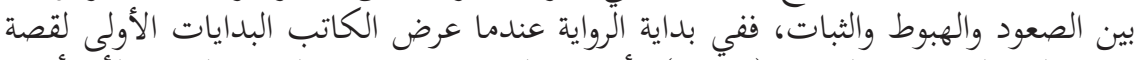

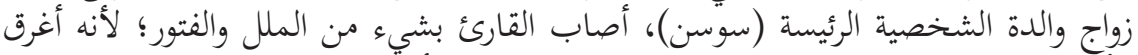

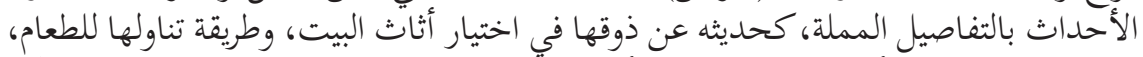

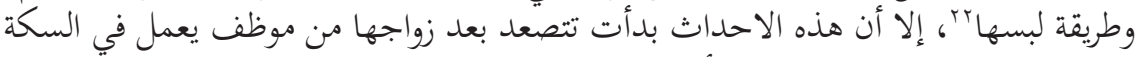

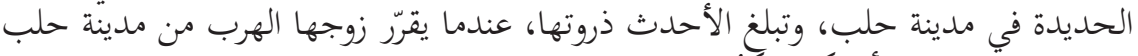

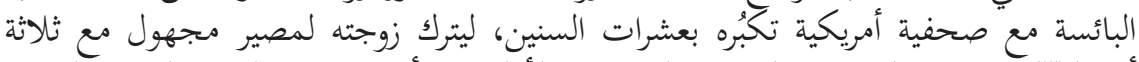

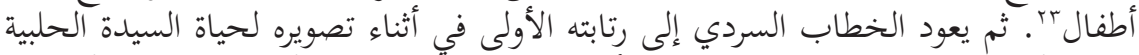

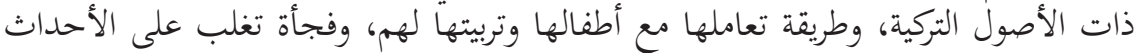

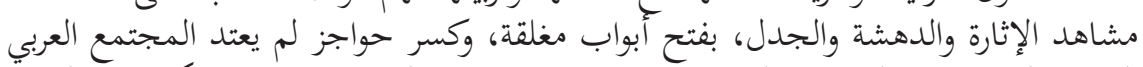

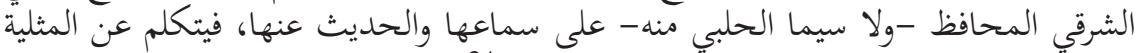

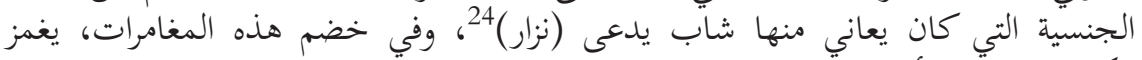

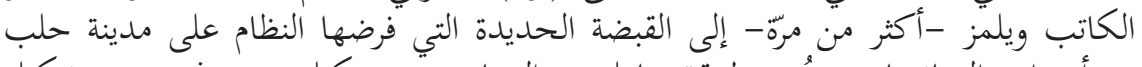

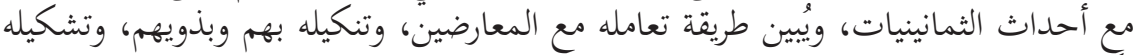

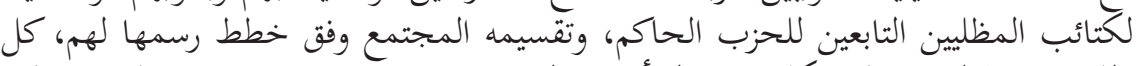

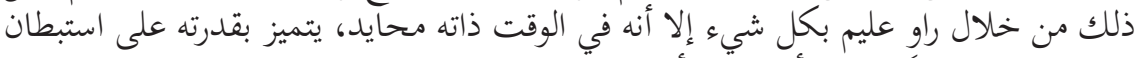

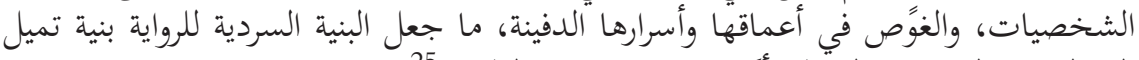

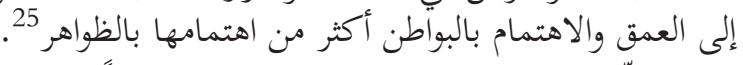

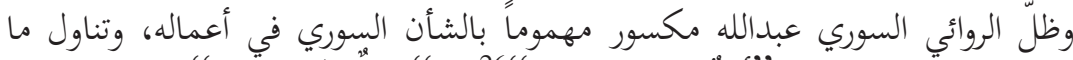

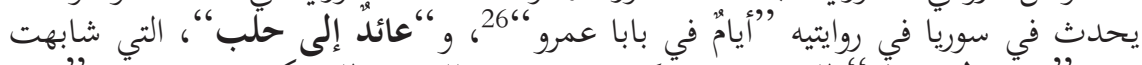

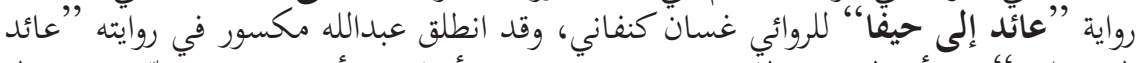

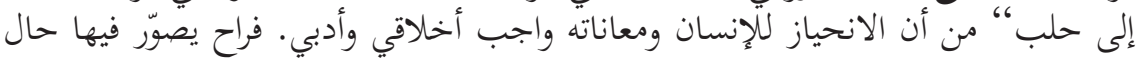

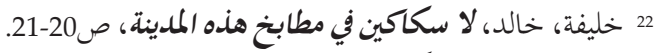

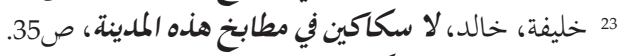

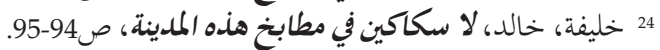

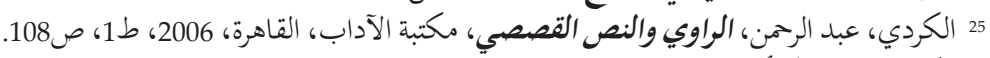

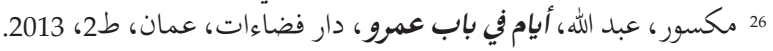


الَّاجئين السوريين والكتائب المسلحة المحاربة، والظواهر البارزة في سوريا، فقدّمَ سيرة مُتخيَّلةً

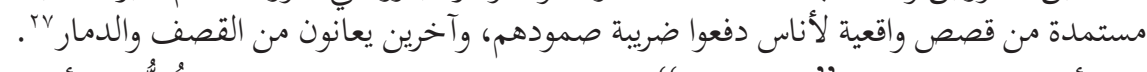

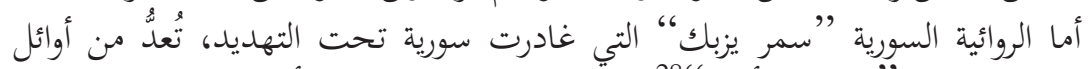

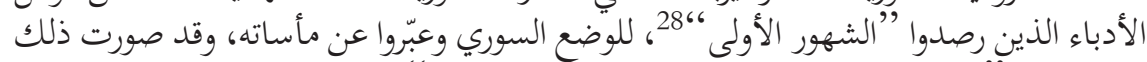

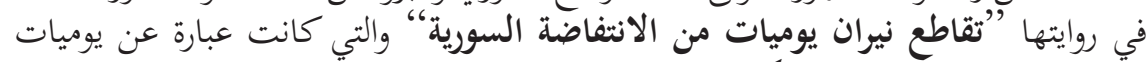

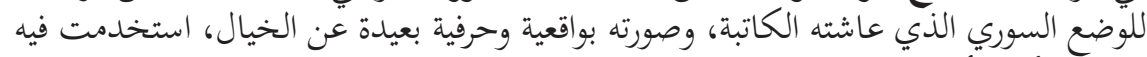

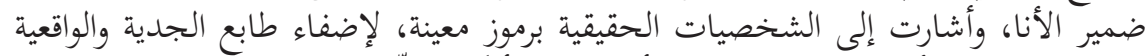

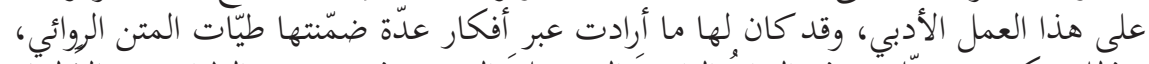

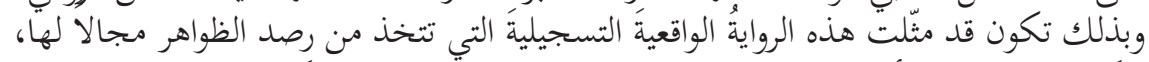

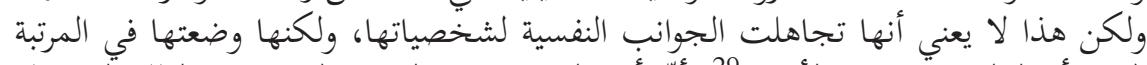

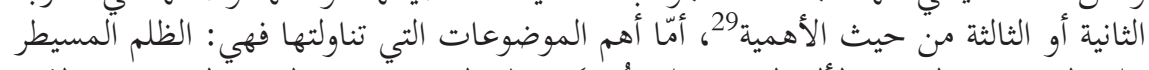

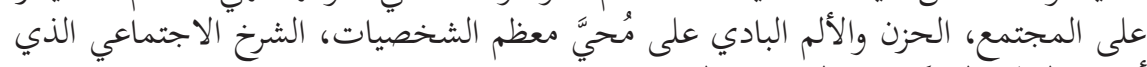

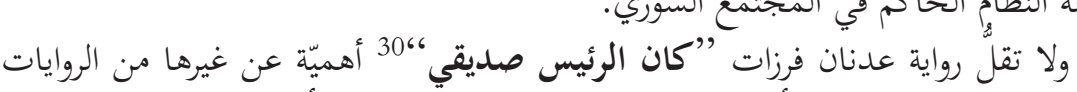

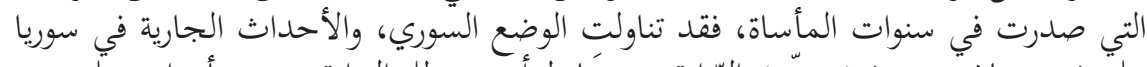

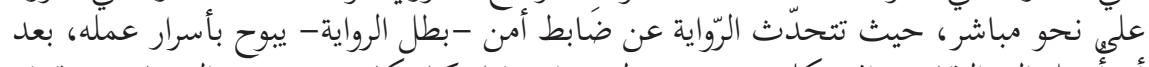

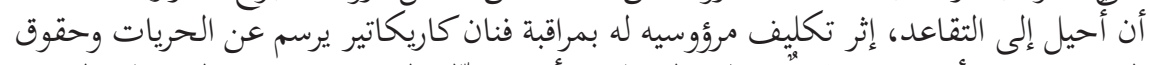

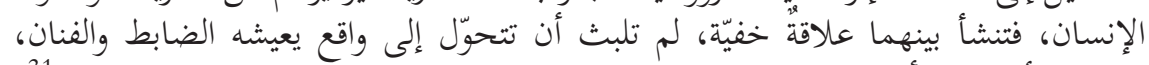

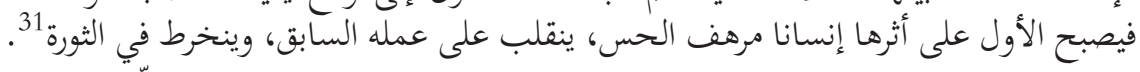

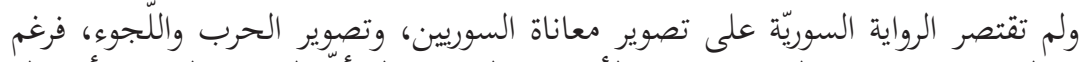

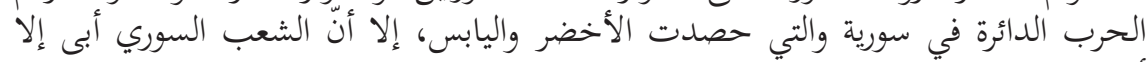

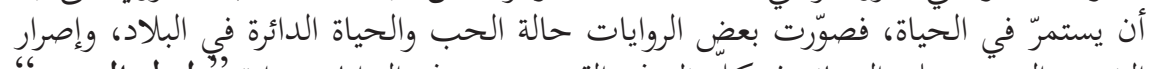

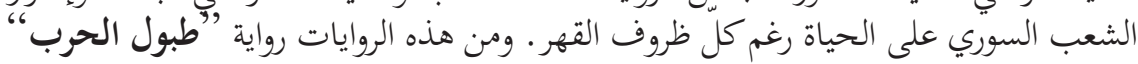

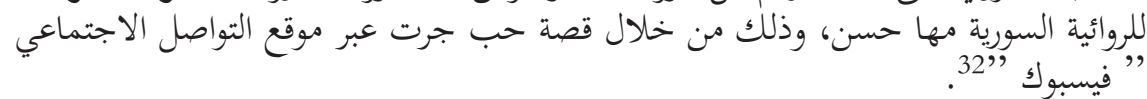

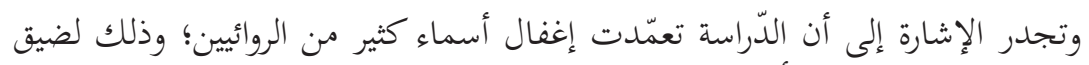

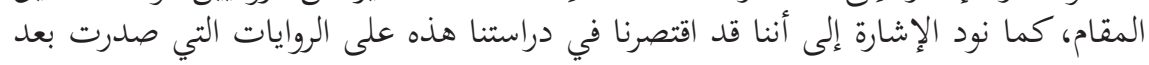

27 عقيل، حنان، روائيون يكتبون التراجيديا الإنسانية على وقع قذائف الماون، جريدة العرب، ع9677، لندن،

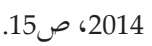

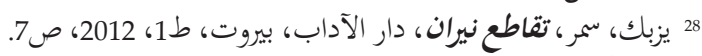

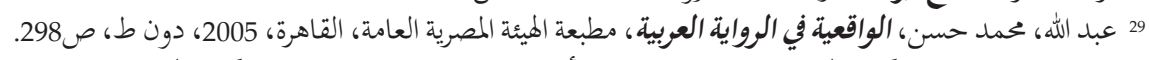

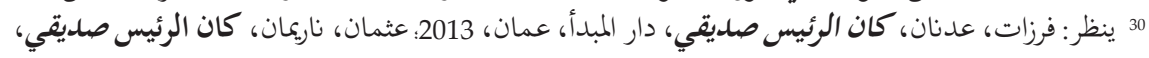

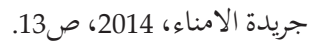
31 المطرود، محمد، رواية كان الرئيس صلديقي" الثورة ضلد الرئيس الصلديق، بجلة أوراق، رابطة الكتاب السوريين،

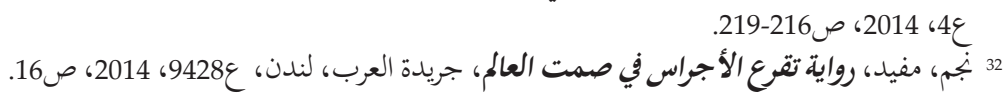




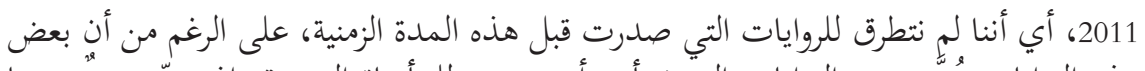

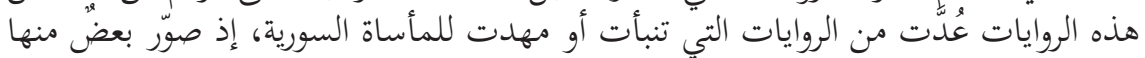

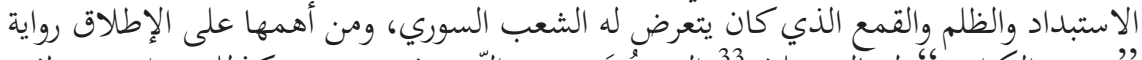
"مديح الكراهية،" لخالد خليفة

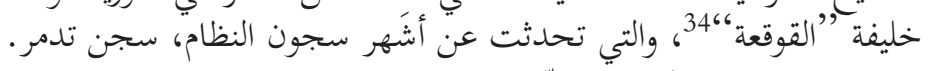

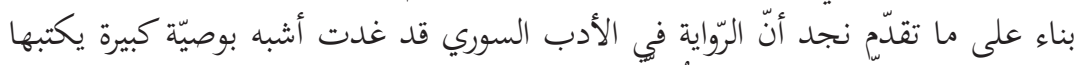

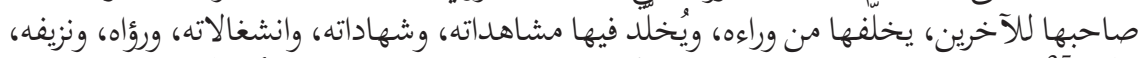

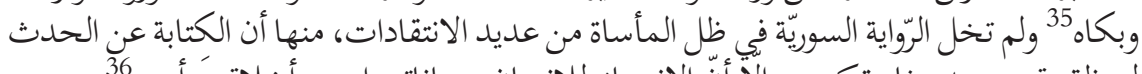

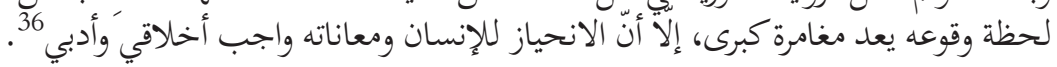

\section{المسرح السوري}

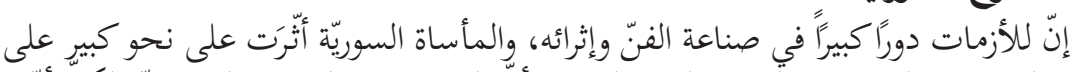

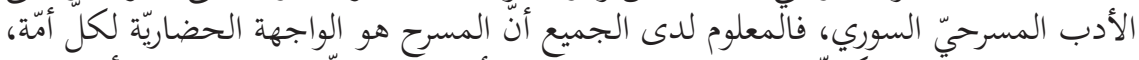

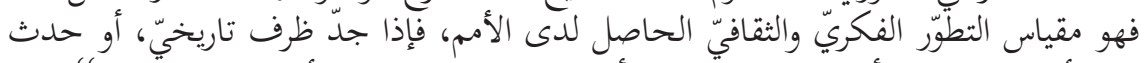

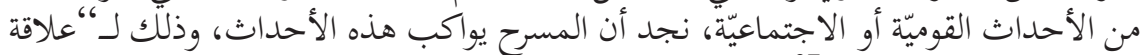

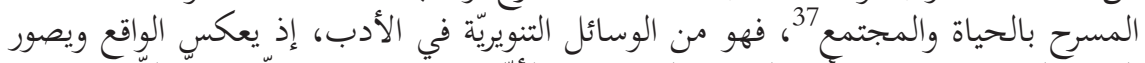

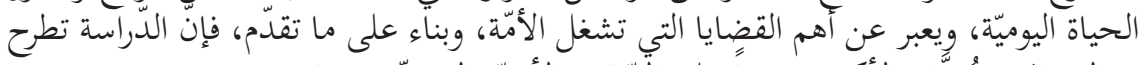

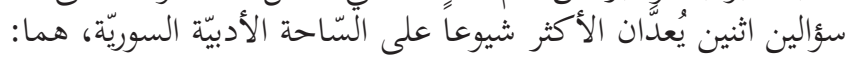
1- هل تغيّر دور المسرح وازدادت مهامه في ظل الأزمة السورية؟

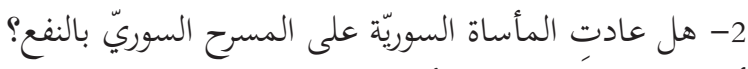

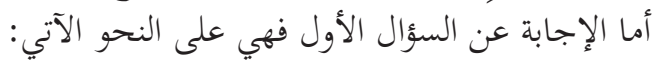

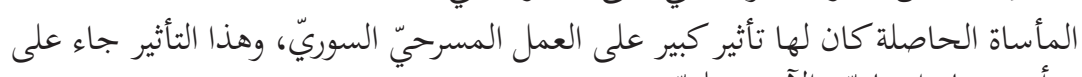
شقيّ، أحدهما: إيجابيّ والآخر سلة سليّي.

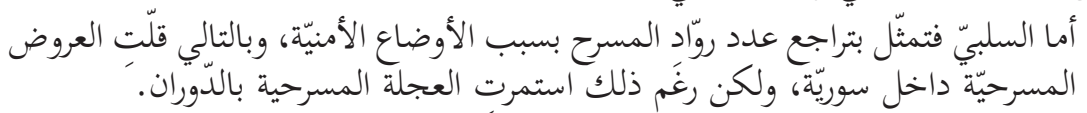

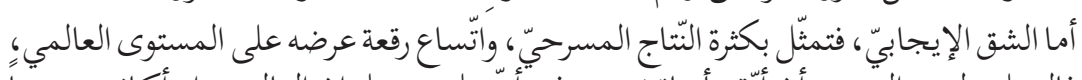

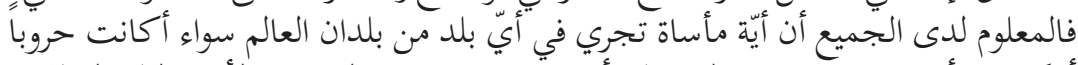

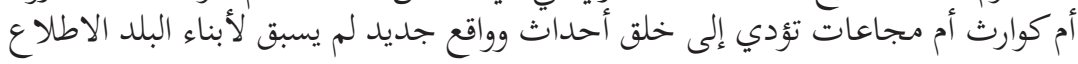

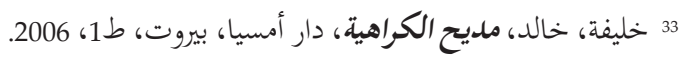

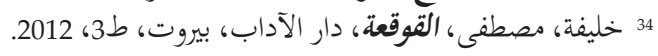

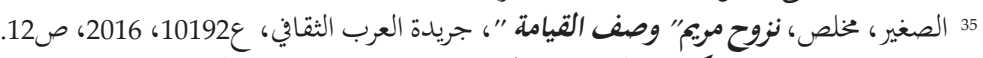

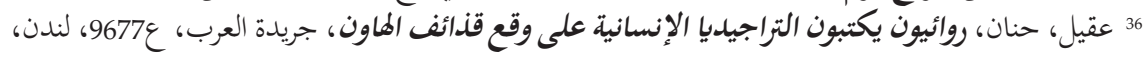
2014، صنان،

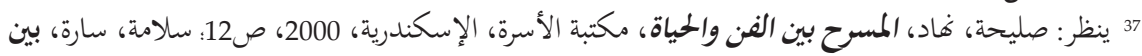

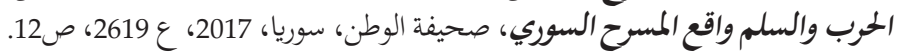




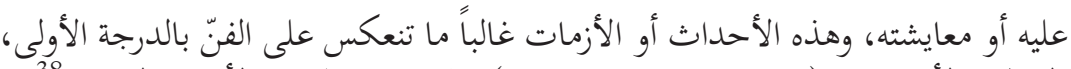

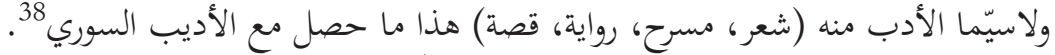

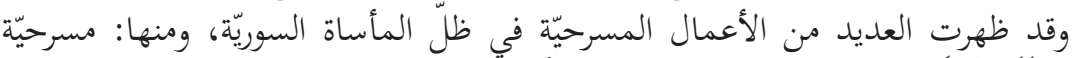

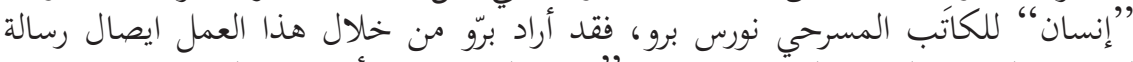

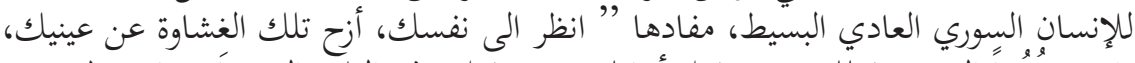

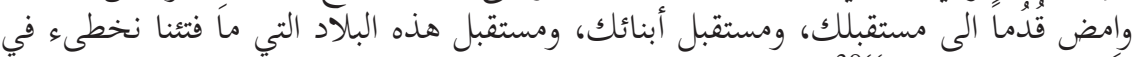

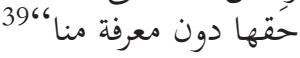

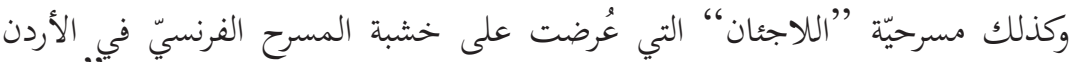

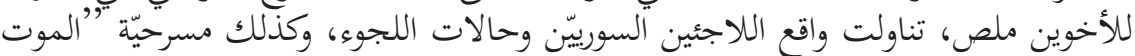

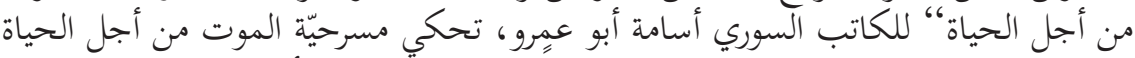

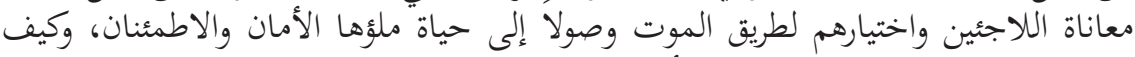

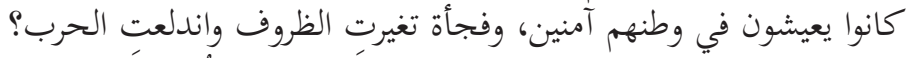

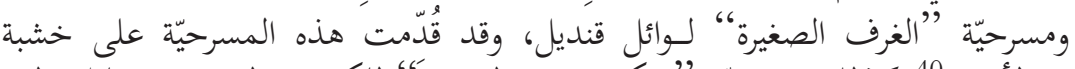

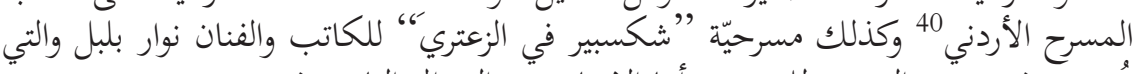

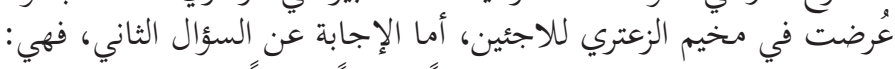

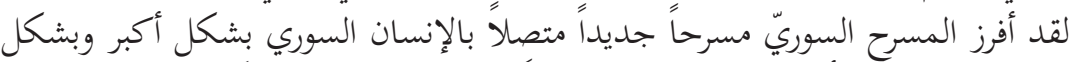

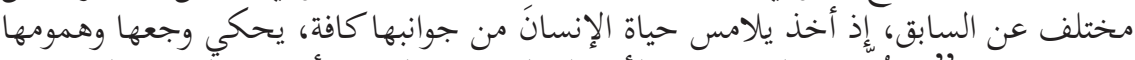

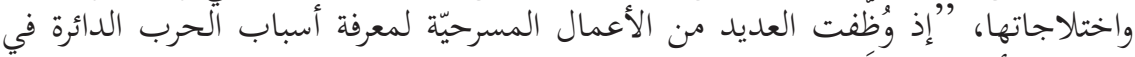

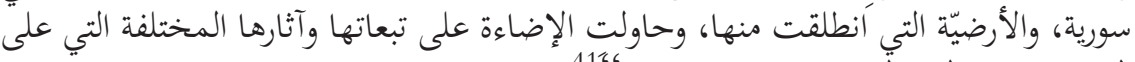

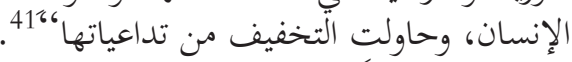

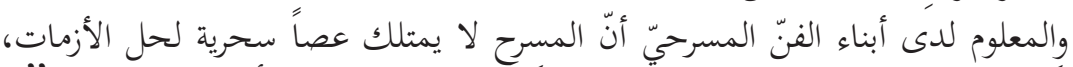

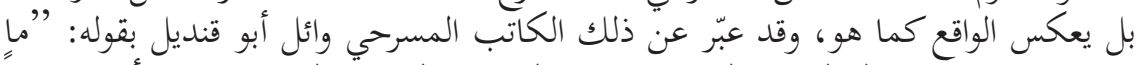

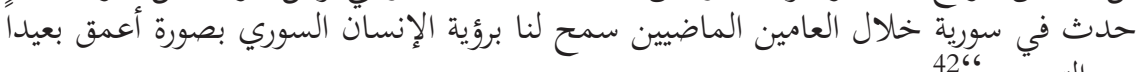

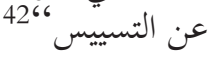

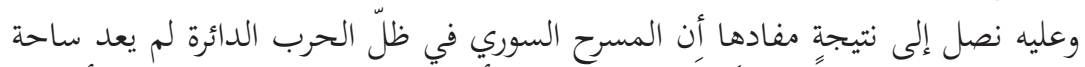

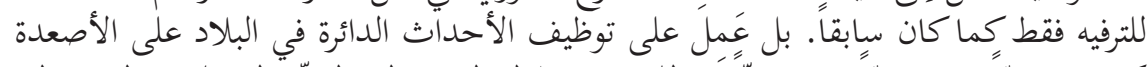

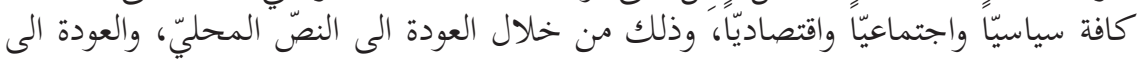

38 الهكار، فراس، الحراك الثقافي السوري في ظل الأزمة مابين العقم الفكري وتسجيل الموقف، موقع تحولات،

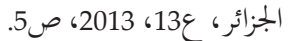

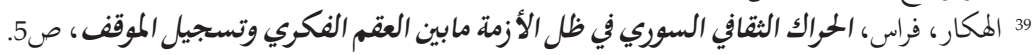

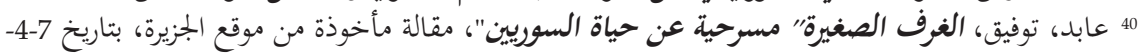
ten.areezajla.www 2019 41 الخضر، آنا عزيز، واقع ومسؤليات الإبداع المسرحي في سورية، جريدة الثورة، دمشق، بتاريخ 7-4-4019، 42 عابد، توفيق، الغرف الصغيرة" مسرحية عن حياة السوريين"، مقالة مأخوذة من موقع الجزيرة، بتاريخ 7-4tten.areezajla.www ،2019 


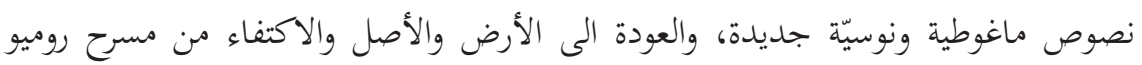

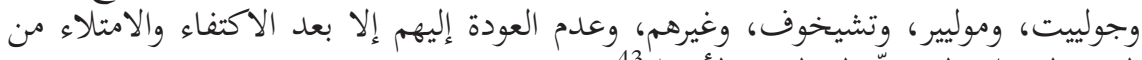

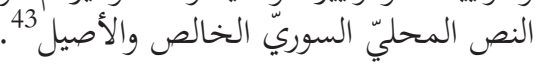

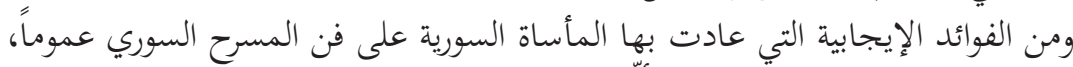

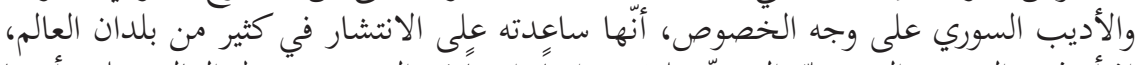

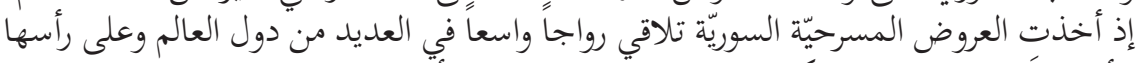

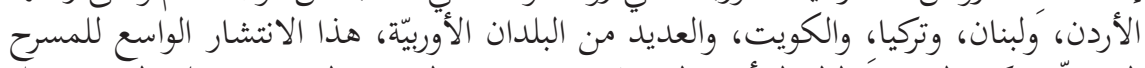

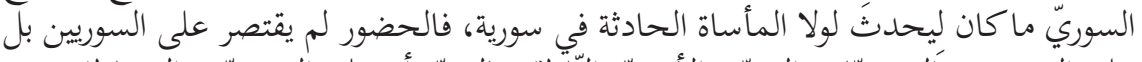

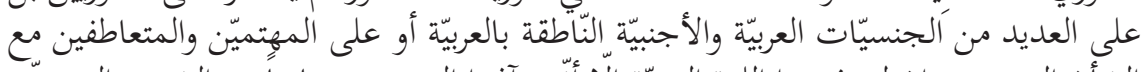

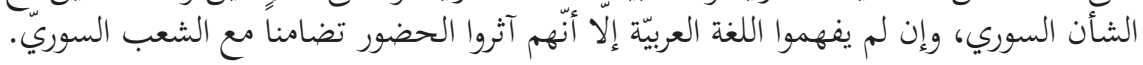

الشعر

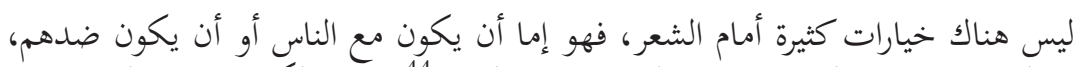

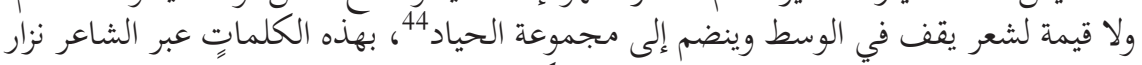

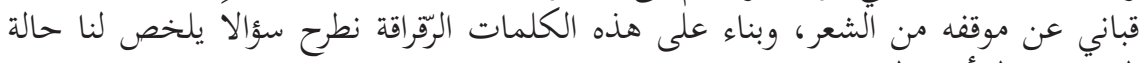

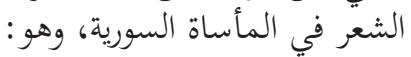

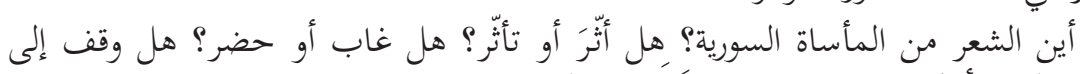

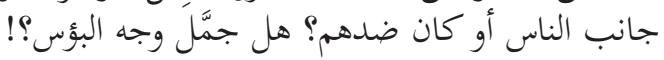

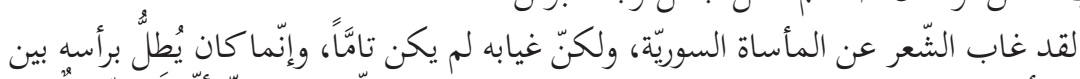

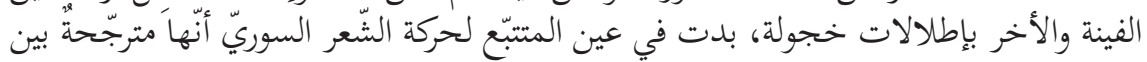

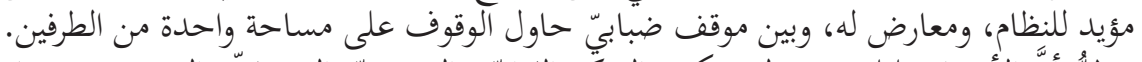

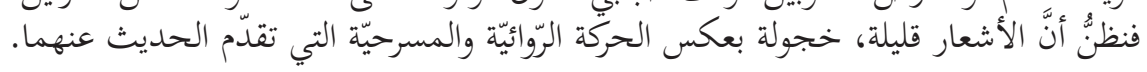

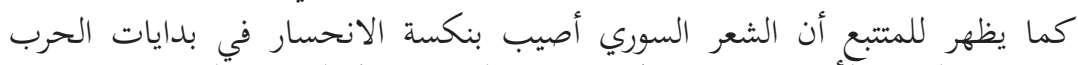

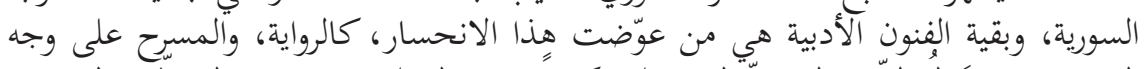

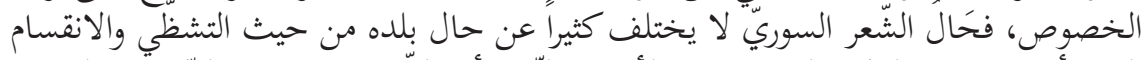

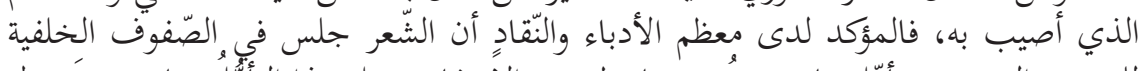

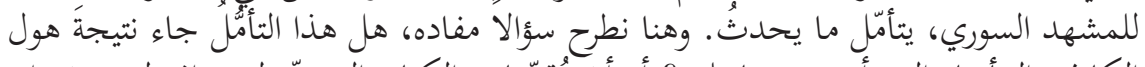

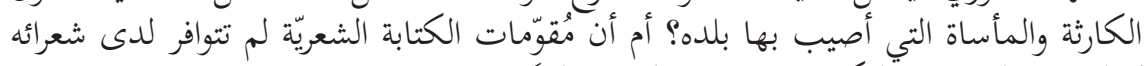

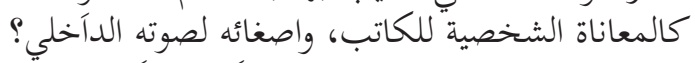

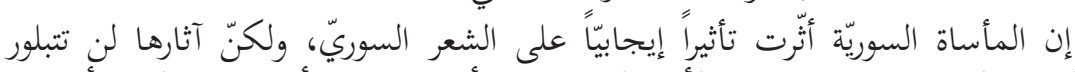

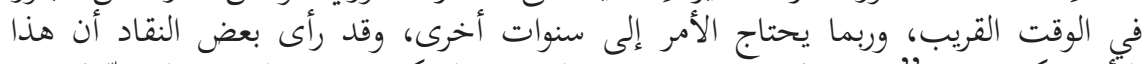

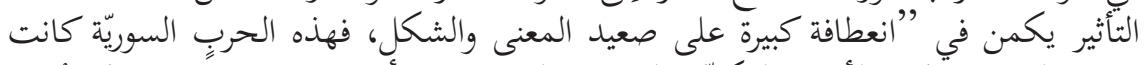

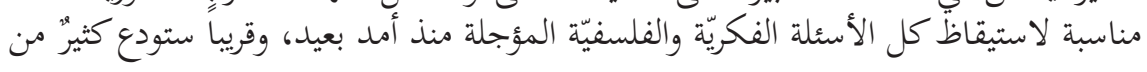

43 الهكار، فراس، الحواك الثقافي السوري في ظل الأزمة مابين العقم الفكري وتسجيل الموقف، مجلة تحولات،

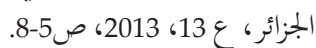

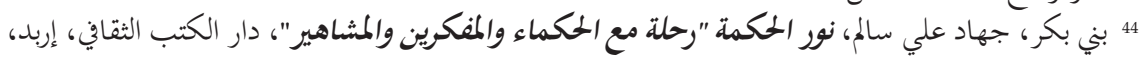

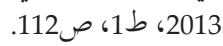




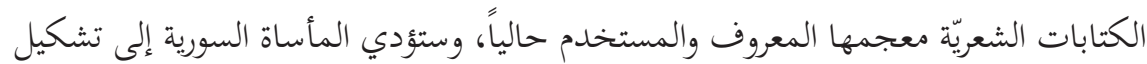

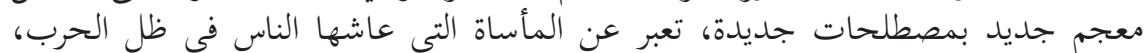

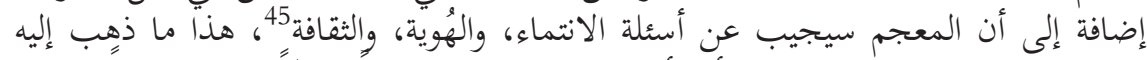

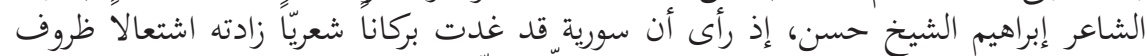

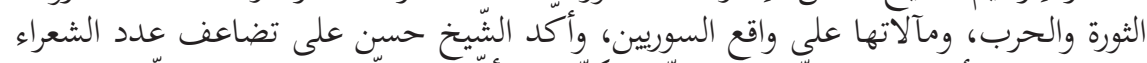

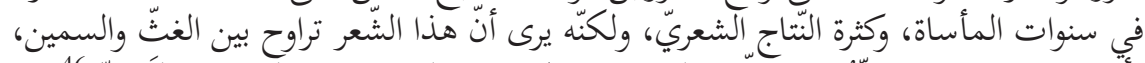

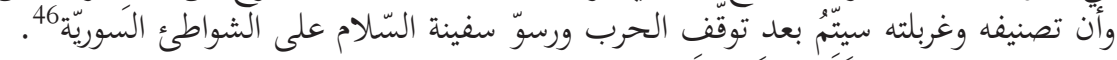

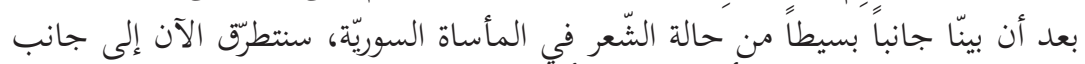

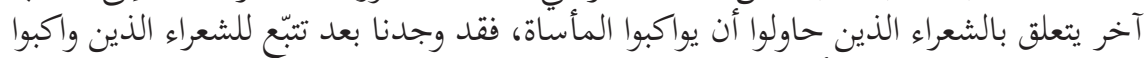

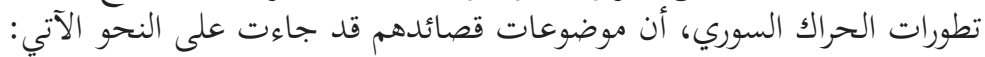

$$
\begin{aligned}
& \text { - - الإنسان السوري في ظل القمع والتهديد. }
\end{aligned}
$$

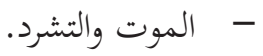

$$
\begin{aligned}
& \text { - - الشرخ الأفقي في بنية المجتمع السوريّ. }
\end{aligned}
$$

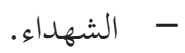

$$
\begin{aligned}
& \text { - - - - الجماعات المسلحة والمتطرفة. }
\end{aligned}
$$

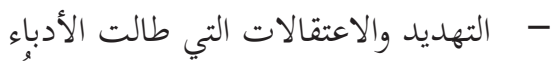

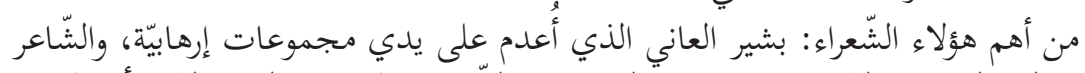

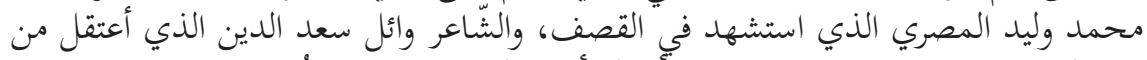

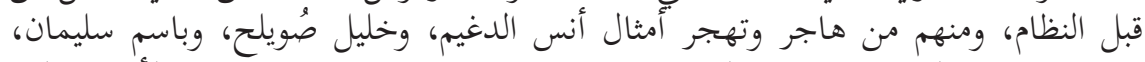

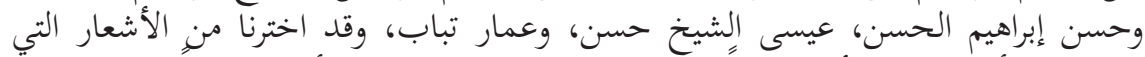

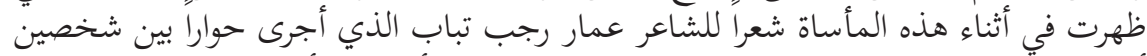

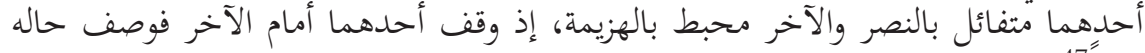
قائلاً

$$
\begin{aligned}
& \text { وتَطُوفُ تِيهًاً بالمدائنَ نَورَََّا }
\end{aligned}
$$

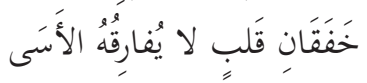

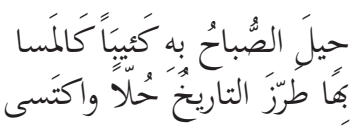

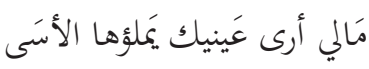

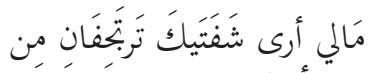

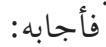

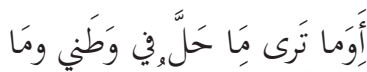

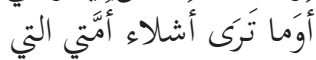

45 إنماعيل، سامر، الشعر السوري بين داخل وخارج "قصيدة واحدة مكتوبة بقلم الحرب"، مجلة الفيصل،

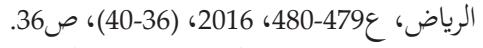

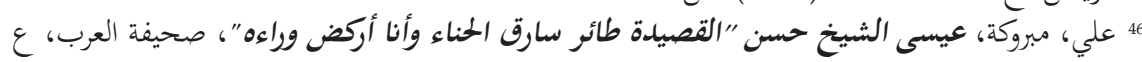

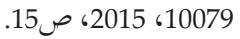

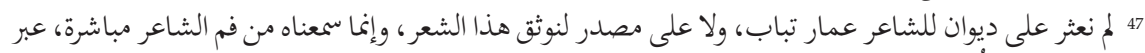

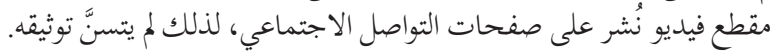




\section{النتاج الأدبي السوري في عيون النقاد}

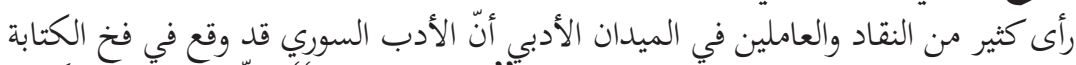

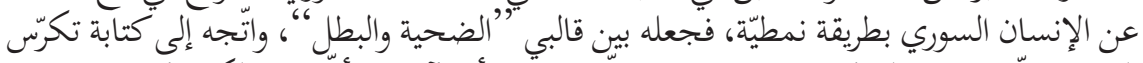

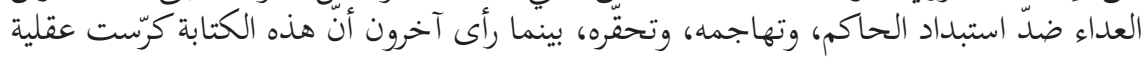

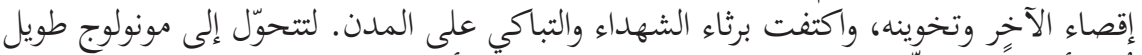

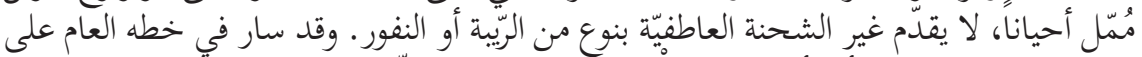

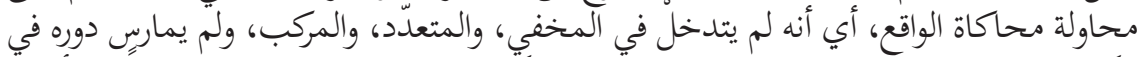

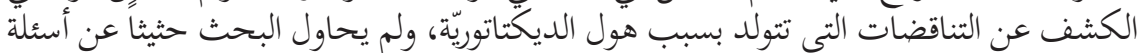

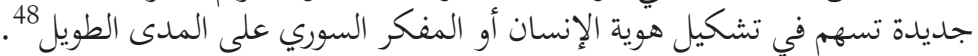

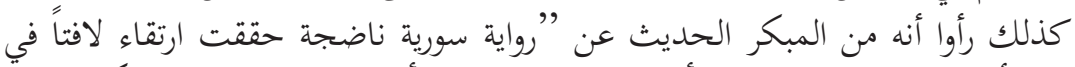

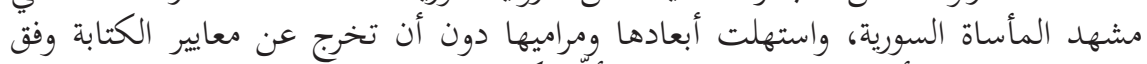

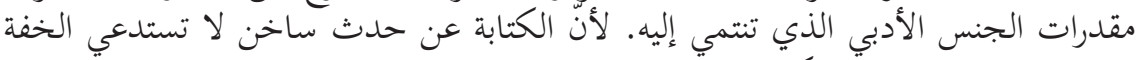

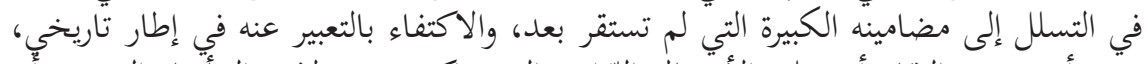

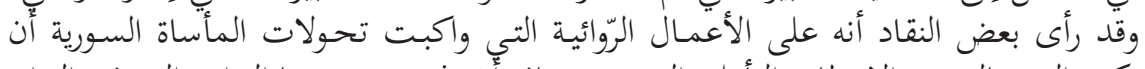

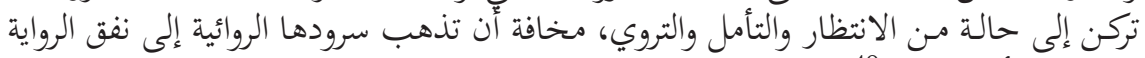

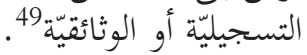

النتائج

بناء على ما تقدّم ذكره في الحديث عن الرواية والمسرح والشعر، نستطيع الوصول إلى الى نتائج عدّة، من أهمّها:

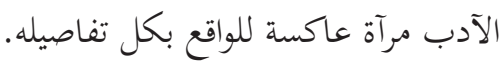

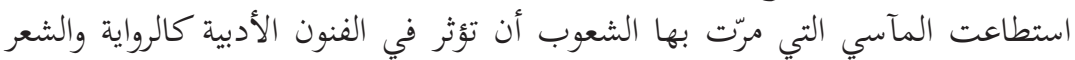
والمسرح.

حاول الأدب رصد مآسي ونكبات بلدانه، إلا أنه واجه صعوبات عدّة، منها:

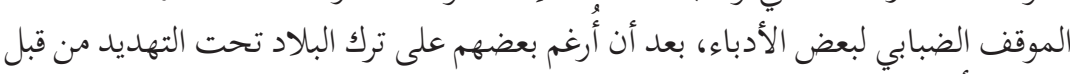
جميع الأطراف.

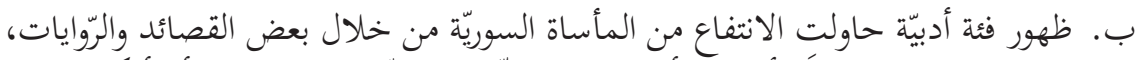

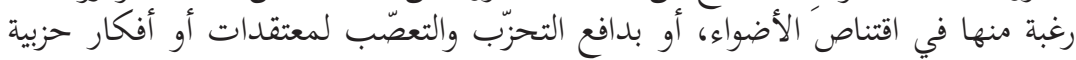
ضيقة تؤمن بها.

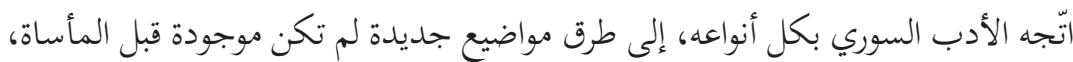

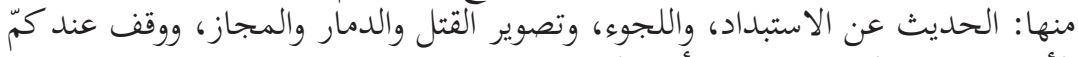

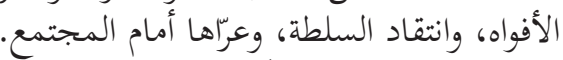

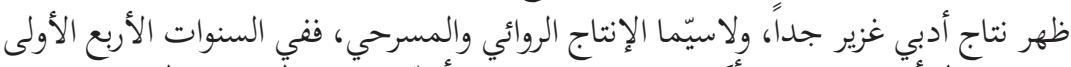

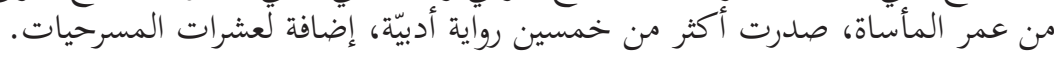

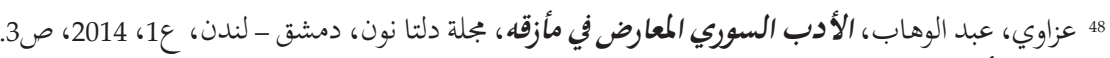

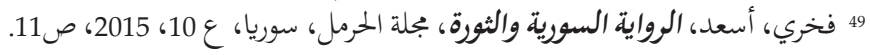




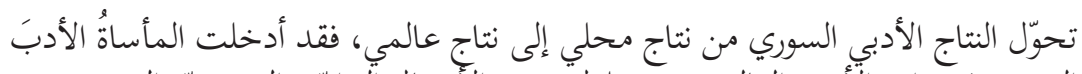

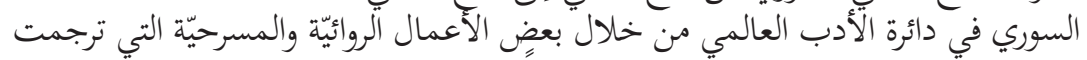

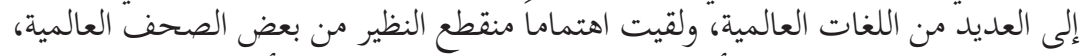

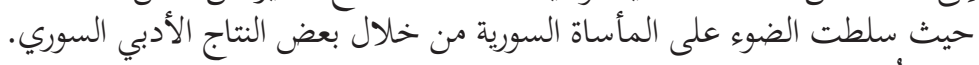

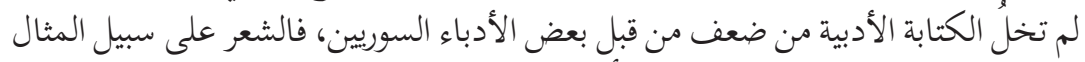
تراجع إلى الصفوف الخلفية للفنية الأنفون الأدبيّة.

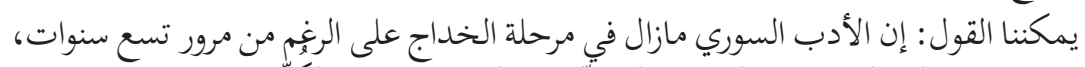

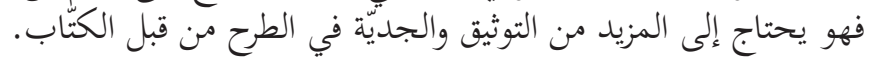

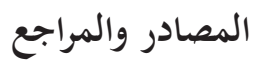

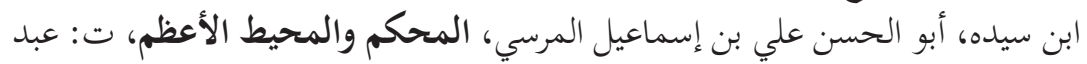

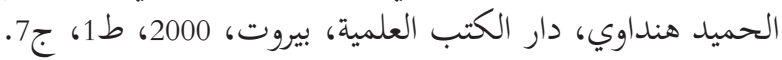

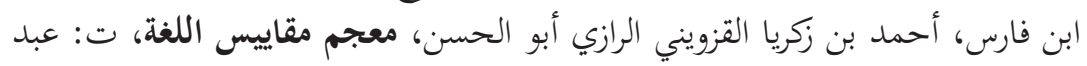

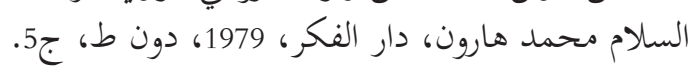

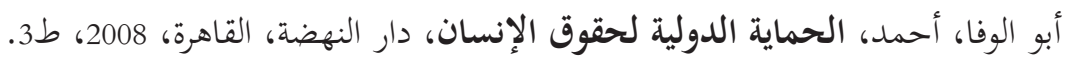

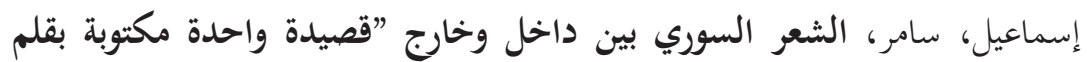

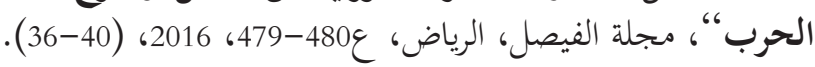

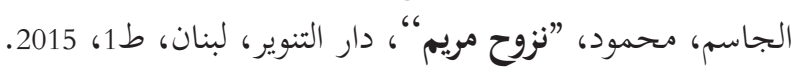

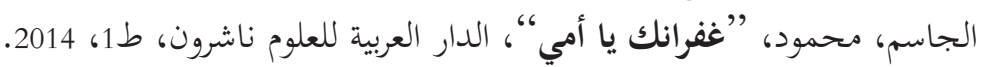

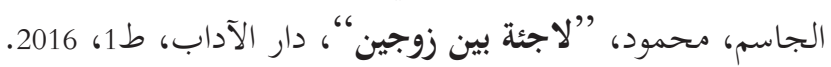

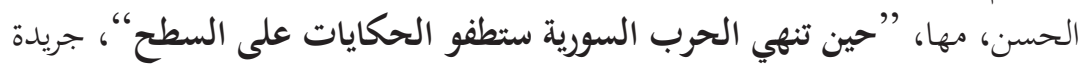

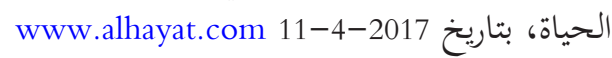
حسين، هيثم، الشعر المفقود والمنشود في زمن الثورة“، موقع الجزيرة، بتاريخ

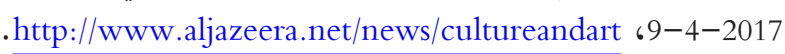
حسيني، خالد، عدّاء الطائرة الورقية، ت: خالد حسيني، دال للنشر والتوزيع، 2010، ط1.

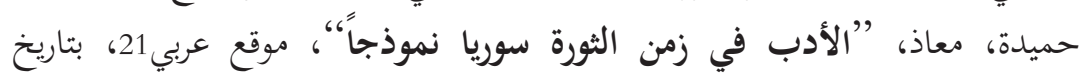
.https://arabi21.com/story 69-4-2017 الخضر، آنا عزيز، "واقع ومسؤوليات الإبداع المسرحي في سورية،"، جريدة الثورة،

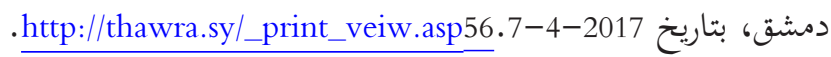

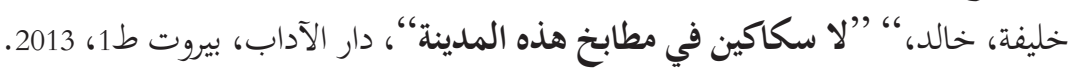

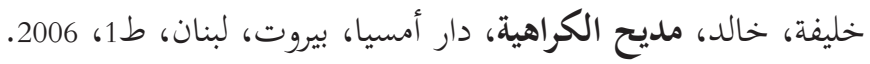

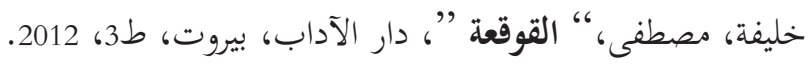




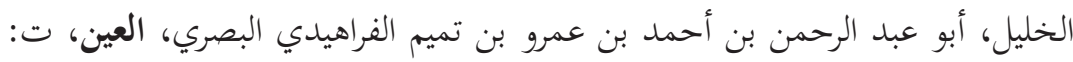

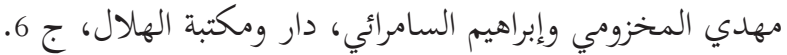

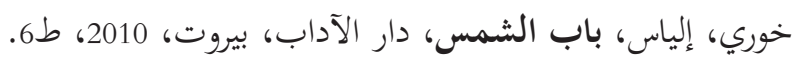

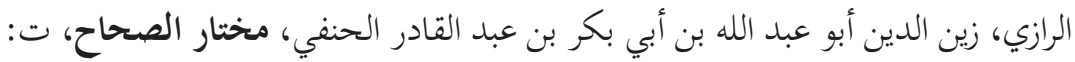

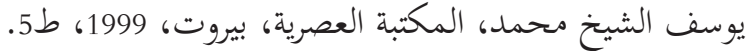
سلامة، سارة، بين الحرب والسلم واقع المسرح السوري، صحيفة الوطن، سوريا، 2017، ع ع 2619.

سليمان، نبيل، "فورة روائية وأسماء تتنافس على على سرد المأساة بجذورها

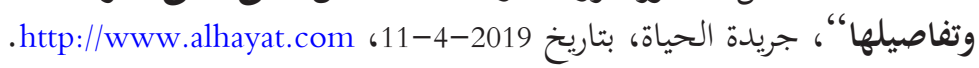

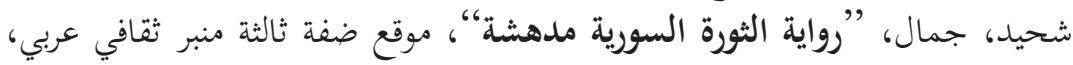

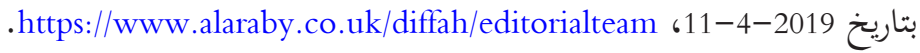

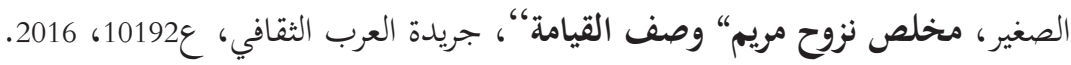

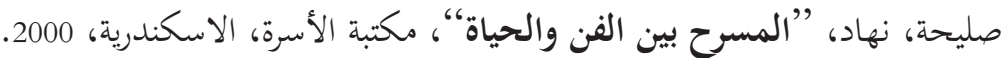

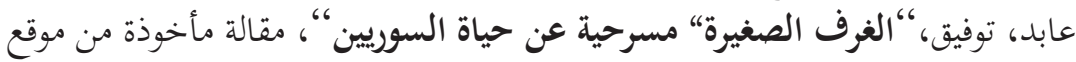

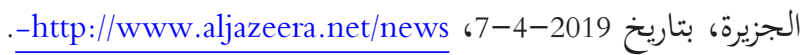
العبدلي، سجا، "الشعراء السويون حين يكون الوطن جريح النص“، بل، مجلة المجلة،

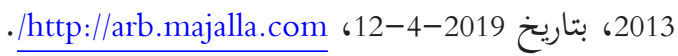

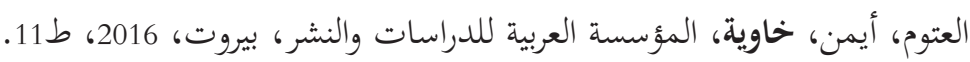

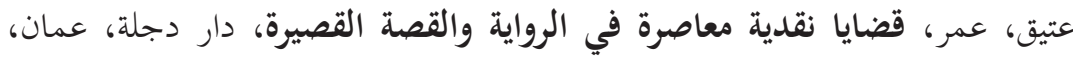
(2016، دون ط.

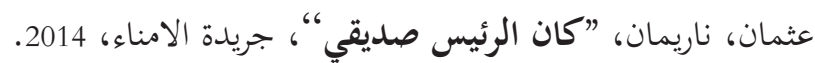

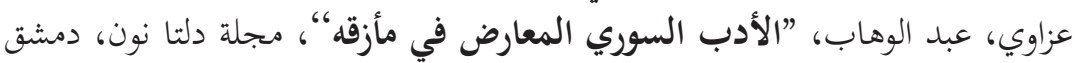
- الندن، ع1 ، 2014.

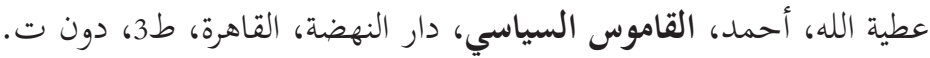

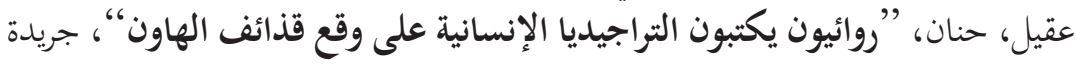

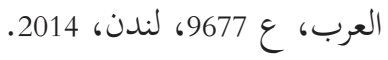
علي، مبروكة، "عيسى الشيخ حسن "القصيدة طائر سارق الحناء وأنا أركض وراءه،"،

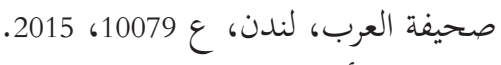
عمر، أحمد مختار عبد الحميد، معجم اللغة العربية المعاصرة، عالم الكتب، بيروت،

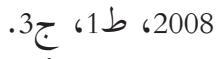
فخري، أسعد، "الرواية السورية والثورة،، مجلة الحرمل، سورية، ع 10، 2015. 
فرزات، عدنان، "كان الرئيس صديقي،، دار المبدأ، الكويت، 2013، 2017-4-7،

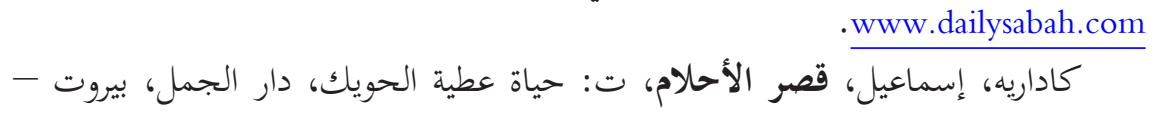

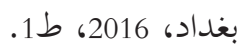

الكردي، عبد الرحمن، الراوي والنص القصصي، مكتبة الآداب، القاهرة، 2006، ط1، أرضان

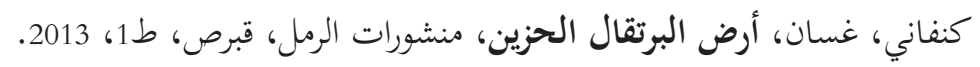

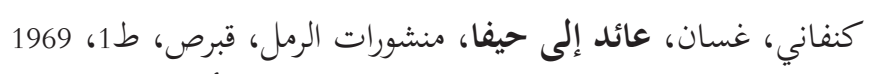

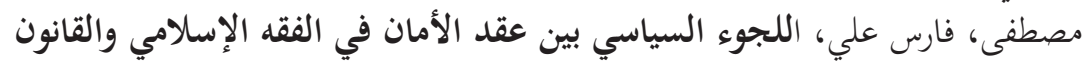

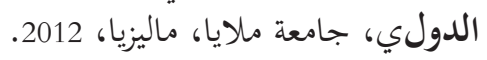

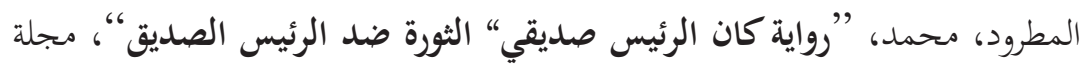

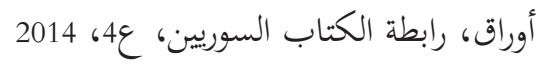

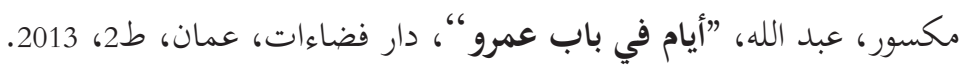

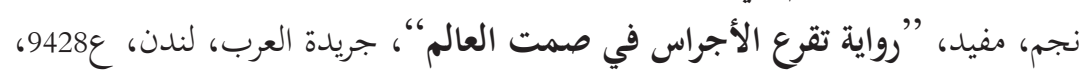

الهكار، فراس، "الحراك الثقافي السوري في ظل الأزمة مابين العقم الفكري وتسجيل

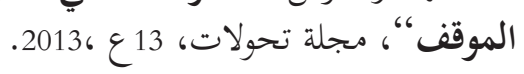

$$
\begin{aligned}
& \text { يزبك، سمر، “" تقاطع نيران"، دار الآداب، بيروت، طاتع، ط13، } 2012 .
\end{aligned}
$$




\section{KAYNAKÇA}

İsmâil, Sâmir. eş-Şi'ri's-Sûri Beyne Dâhili ve Hârici Kasîdetin Vâhidetin Mektûbetin Bikalemi'l-Harb. Riyâd: Mecelletü'1-Faysal, 2016.

Câsim, Mahmud. Nüzûhu Meryem. Lübnan: Dâru't-Tenvîr, 2015.

Câsim, Mahmud. Gufrâneke Yâ Ummî. ed-Dâru'l-Arabiyyetu li'l-'Ulûm Nâşirûn, 2014.

Câsim, Mahmud. Lâcietun Beyne Zevceyn. Dâru'l-Âdâb, 2016.

Hasan Meha. Hîne Tenhi'l-Harb al-Suriyyetu Setatfu'-Hikâyât 'Ala's-Sathi. Cerîdetü'1Hayât, 2017. wwww. alhayat.com

Hüseyin, Heysem. eş-Şi'ril-Mefkûd ve'l-Menşûd fî Zemeni's-Sevre. Mevki'u'l-Cezîre, 2017. http://www.aljazeera.net/news/cultureandart

Hamîde, Muaz. el-Edeb fì Zemeni's-Sevreti Suriye Nemûzecen. Mevk'iu Arabi 21, 2017. https://arabi21.com/story/

Hıdır, Âna Azîz. Vâk'iu ve Mes'uliyyâtu'l-İbda'il-Mesrahi fî Suriye. Cerîdetü's-Sevre: Dimaşk, 2017. http://thawra.sy/_print_veiw. asp56.

Halîfe, Halid. Lâ Sekkâkîn fî̀ Metâbihi hâzihi'l-Medîne. Beyrut: Dâru'1-Âdâb, 2013.

Halîfe, Halid. Medîhu'l-Kerâhiyye. Beyrut: Dâru Emsiyâ, 2006.

Halîfe, Mustafa. el-Kavki'a. Beyrut: Dâru'l-Âdâb, 2012.

Selâme, Sâre. Beyne'l-Harbi ve's-Silmi Vak'iu'l-Mesrahi's-Sûriyy. Suriye: Sahîfetü'lVatan, 2017.

Süleymân, Nebîl. Fevretün Rivâiyyetün ve Esmâun Tetenâfesu Âla Sirdil-Me'sât Bicüzûriha ve Tefâsîliha. Cerîdetü'l-Hayât, 2019. http://www.alhayat.com.

Şehîd, Cemâl. Rivâyetü'-Sevreti's-Suriyyeti Müdhişeten. Mevk'iu Diffeti Sâliseti Minberin Sekâfiyyin Arabiyyin, 2019. https://www.alaraby.co.uk/diffah/editorialteam.

Sagîr, Muhlis. Nuzûhu Meryem Vasfu'l-Kıyâme. Cerîdetü'l-Arabi's-Sekafi, 2016.

Salîha, Nihad. el-Mesrah Beyne'-Fenni ve'l-Hayât. Mektebetü'-Üsre, el-İskenderiyye, 2000.

Âbid, Tevfik. el-Ğuref es-Să̆îra Mesrahiyyetun Ân Hayâti's-Sûriyyin. Makaletun Me'hûzetun Min Mevk'i'l-Cezîre, 2019. http://www.aljazeera.net/news

Abdelî, Secâ. eş-Şu'arâ es-Sûriyyûn Hîne Yekûnu el-Vatan Cerîhu'n-Nass. Mecelletü'lMecelle, 2013. http://arb.majalla.com/

Osman, Nerimân. Kâne'r-Reîsu Sadîkî. Cerîdetü'l-Umenâ, 2014.

Âzavî, Abdulvehhab. el-Edeb es-Sûriyy el-Meârıd fî Me'zekıhi. Dımeşk-Londra: Mecelletu Delta Nûn, 2014.

Akîl, Hanân. Rivâiyyun Yektûbune et-Tirâcediya el-İnsaniyye Alâ Vak'i Kazâifi'l-Havan. Londra: Cerîdetü'l-Arab, 2014. 
Ali, Mebrûke. İsa eş-Şeyh Hasan "el-Kasîde Tâirun Sariku'l-Hana' ve Ene Erkudu verâehâ. Londra: Sahîfetü'1-Arab, 2015.

Fahri, Es'ad. er-Rivâyetu's-Sûriyye ve's-Sevre. Suriye: Mecelletü'l-Hirmal, 2015.

Ferzat, Adnan. Kâne'r-Rê̂su Sadîkî. Kuveyt: Dâru'l-Mebde', 2013. www.dailysabah.com

Matrûd, Muhammed. Rivâyetun Kane'r-Reîsu Sadîkî", es-Sevretu Dıdda'r-Reîs esSadîk. Mecelletü Evrâk, Râbitatü'l-Kitabi's-Sûriyyin, 2014.

Meksûr, Abdullah. Eyyam fî Babi Amr. Amman: Dâru'l-Fadaât, 2013.

Necm, Müfîd. Rivâyetun Tekra'u'l-Ecrâs fí Stmti'l-Alem. Londra: Cerîdetü'l-Arab, 2014.

Hekkâr, Firas. el-Harrâku's-Sakafì es-Sûriyy fî Zilli'l-Ezmeti Mabeyni'lakmil-Fikrî ve Tescilü'l-Mevkif. Mecelletü'Tahavvulat, 2013.

Yezbek, Semr. Takâtu'u Nîran. Beyrut: Dâru'l-Âdâb, 2012.

Mengestu, Dinaw. The Beautiful Things That Heaven Bears. Riverhead Books: New York, 2007. 